
3 Research Square
Preprints are preliminary reports that have not undergone peer review.
They should not be considered conclusive, used to inform clinical practice,
or referenced by the media as validated information.

\title{
Current trends and future perspective of renewable energy research in Africa; A Bibliometric analysis
}

Sandylove Afrane

Tianjin University

Jeffrey Dankwa Ampah ( $\sim$ jeffampah@live.com )

Tianjin University https://orcid.org/0000-0002-0985-151X

Emmanuel Mensah Aboagye

Zhongnan University of Economics and Law

\section{Research Article}

Keywords: Africa, renewable energy, bibliometric analysis, research trend, electricity

Posted Date: July 28th, 2021

DOI: https://doi.org/10.21203/rs.3.rs-757073/v1

License: () (i) This work is licensed under a Creative Commons Attribution 4.0 International License. Read Full License 


\section{Abstract}

Several countries across the African continent have been challenged with energy crisis for decades. A growing number of studies have identified renewable energies as a sustainable way for Africa to address its persisting energy situation, as the continent has in abundance some of the popular renewable energy sources. However, little has been reported in the body of literature about this growing research area's global mapping and knowledge domain. By bridging this gap in research, it becomes easy to identify which authors, countries, organizations/institutions are likely to produce research that paves the way for the easy penetration of renewable energy into the existing African energy mix. Moreover, potential investors in the continent's renewable energy can easily identify the most popular and advantageous renewable energy to invest in. Thus, the current study seeks to achieve these aims by conducting a bibliometric analysis on 1037 publications extracted from the Web of Science Core Collection using the VOSviewer software. The results from the study revealed a growing interest in Africa's renewable energy, with a $200 \%$ increase within the last five years. The most productive journal, institution, and country in this subject have been Energy Policy, University of Cape Town, and South Africa, respectively. Research hotspots under different study themes also revealed that 'solar energy, ' $\mathrm{CO}_{2}$ emissions,' and 'rural electrification' are hot issues that have gained maximum attention over the years. Results from the current study provide a paradigm for the development of Africa's renewable energy sector.

\section{Introduction}

\subsection{Background}

Over-dependence on conventional fossil fuels and the sharp increase in demand for energy worldwide pose a major challenge to sustainable development. Due to the high population growth rate and economic development, global energy demand is expected to more than double by 2050 (Lewis \&Nocera 2006 , Whitesides \&Crabtree 2007). At the present rate of demand, gasoline will be depleted in 50 years, natural gas in 65 years, and coal in 200 years (Soetaert \&Vandamme 2009). The use of fossil fuels also contributes massively to the emission of greenhouse gases (GHG) and other pollutants into the atmosphere. These challenges have ignited the interest of international bodies and local governments in renewable energy sources. As part of the sustainable development goals, the United Nations has made a great effort to combat this problem by setting a new target to "promote affordable, reliable, sustainable, and modern energy for all" by 2030 (Sustainable Development Goal 7). Most countries, both developed and developing, have made huge investments in renewable energy conversion technologies to alleviate potential energy crises and protect the environment. Emerging economies, particularly China and India, are actively leading the global renewable energy shift by demonstrating the strongest commitment to wind and solar development (REN21 2017). The overall global investment in 2017 was $\$ 279.8$ billion (excluding hydropower stations higher than $5 \mathrm{MW}$ ), with a year-on-year increase of $2 \%$ (IEA 2018). In 2017, global renewable energy power consumption increased at a rate of 5.62\% per year, which was 2.95 times faster than primary energy consumption (BP 2020). Forecasts by researchers show the share of renewable energy sources in the global energy supply would reach $34.7 \%$ by 2030 and $47.7 \%$ by 2040 (Demirbas 2009).

Energy report from 2019 indicates that Africa accounts for just 4\% of global power supply investment despite the large population of about 1.29 billion people residing in this region (IEA 2019). In order to adapt to the rapid rate of economic growth, the total power generation demand in Africa has been increasing substantially, with a growth of 18\% projected in 2025 compared to 2016 (Xu et al. 2019). Compared to the rest of the world, Africa has not fully exploited the benefits of renewable energy sources due to technical and economic constraints as well as social factors like political instability and unclear policies. According to de Vries et al. (2007), the average growth rate of global modern renewable energy production surpasses that of Africa by $8.43 \%$ from $1996-2018$. In 2017, the African Development Bank reported that the continent's estimated power generation potential is $350 \mathrm{GW}$ for hydroelectric, $110 \mathrm{GW}$ for wind, $15 \mathrm{GW}$ for geothermal, and $1000 \mathrm{GW}$ for solar (African Development Bank 2017). Despite the high renewable energy potential in most African countries, over 548 million people across the continent still have no access to electricity, and 900 million rely on traditional solid biomass for cooking (IEA 2020 , IEA et al. 2020). Moreover, problems like high population growth, low adaptability to change, and impending water crises make Africa the most vulnerable continent to the impacts of global warming and climate change (Boko et al. 2007). Therefore, the development of renewable energy in Africa is crucial for securing energy independence and improving socio-economic development of countries while reducing pollution at both local and global levels, thus lessening the impact of climate change.

This insight has caused some of the largest economies in Africa, such as South Africa, Kenya, and Morocco, to actively open up investment opportunities in this space within their countries. Examples of major renewable energy projects that aim to be at the top of global rankings for installed renewable capacity include; the Noor concentrated solar power plant in Morocco, the Lake Turkana wind farm in Kenya, and the Grand Renaissance Dam in Ethiopia (total planned capacities of 500, $310 \mathrm{MW}$, and $6.45 \mathrm{GW}$ respectively) (Hafner et al. 2018). Even though the renewable energy market in most of Africa is still in its emerging state, more and more countries have made efforts to set targets for renewables. Senegal and Ghana have set to reach $20 \%$ and $10 \%$ share of renewables in total power generation, respectively (Hafner et al. 2018). The development of renewable energy sources in Africa shows that hydroelectric power was the primary source of green energy use prior to the millennium (i.e., 1990-1999). However, from 2000-2018, growth in renewable energy consumption has been dominated by solar and wind, particularly from 2015-2018 (BP 2020).

The growing interest in this field of research is evident by the significant number of studies. Some researchers have reviewed literature in this field from different perspectives. Aliyu et al. (2018) reviewed the prospects of four major renewable energy sources-hydro, solar, wind, and biomass- for each of the three leading countries in Africa; South Africa, Egypt, and Nigeria. This paper revealed that (1) South Africa has the optimal model for addressing its energy issue by utilizing wind and solar energy among the three countries (2) Egypt's utilization of hydropower and an emerging solar power base is also encouraging. (3) Despite the great potential of renewables, Nigeria has weak hydro, solar, and wind power in that order. In a systematic review of electricity planning and implementation in sub-Saharan Africa, Trotter et al. (2017) found that $63 \%$ of relevant publications advocate for renewable energy technology to solve their challenges. This study also indicated that adequate policy design, sufficient funding, and favourable political conditions are frequently stated success criteria for electricity in Sub-Saharan Africa. A current review by Mutezo \&Mulopo (2021) evaluated current literature on Africa's energy transition to see if it is 
facilitated and directed by circular economy concepts. According to their findings, Africa's energy consumption is expected to rise considerably, owing to industrialisation and population expansion. The majority of energy in Sub-Saharan Africa comes from renewable sources, although countries like Algeria, Nigeria, Morocco, South Africa, and Egypt (the Big Five) remain highly reliant on fossil fuels.

Although numerous studies have been conducted, little attention has been paid to investigating the current status and emerging trends of research in this field. Expert review papers have provided an overview of renewable energy research in Africa, although they are limited in certain aspects, such as study areas, subjects, and technologies. The bibliometric method is one of the quantitative analysis tools that have been used extensively by researchers across various disciplines. Bibliometrics is a very effective scientific research tool used to chart the distribution, scalar relationship, and adjust the regulation of literature and knowledge to assess the structure and characteristics of a field of study (Hood \&Wilson 2001, Mao et al. 2015b). In the case of renewable energy study, Mao et al. (2015a) used the bibliometric method to quantitatively and qualitatively evaluate the global trend of research literature related to alternative energy from 1994 to2013. Casado et al. (2014) studied Spanish-Chinese partnership in renewable energy using bibliometrics to analyse subject areas prompting the greatest interest among researchers in the two countries. Pouris (2016) assessed the performance of the energy (fossil fuels and renewable energy) research in South Africa from 2003 to 2013 to identify relevant issues of interest and compare the country's performance with those of other countries through a bibliometric analysis. This current paper applies bibliometric analysis in mapping literature on renewable energy in Africa from 1999-2020 to evaluate past and current trends of research and determine the key areas in this field of research with the following specific activities: (1) measure the quantity and quality of research materials, distribution in journals and subject areas, citation patterns and performance of authors, organizations and countries involved; (2) analyse collaborations among authors, organizations and countries; (3) discover research hotspots in the subject area based on keyword analysis. The study then presents predictions about potential research directions on renewable energy in Africa based on computed results.

\subsection{A brief overview of the energy situation in Africa and policy development for renewable energy}

Africa's population and economic development have sustained rapid growth over the years, and this has had far-reaching regional and global implications for the continent's energy sector. In 2018, Africa's Gross Domestic Product (GDP) was estimated at 7 trillion dollars, projected to reach 17 trillion dollars by 2040 (IEA 2019). Higher GDPs imply higher energy needs as major sectors of the economy such as transportation, industries, and agriculture increase their consumption rate. The 54 countries in Africa have been grouped into four main regions; North, East, West, Central, and Southern Africa. Different regions experience different energy issues based on their population and GDP. For instance, in 2013, North Africa's GDP per capita was about three to five times higher, with fewer than $2 \%$ of the population lacking access to electricity. In comparison, about half of the population in West Africa, three quarters in East Africa, and the majority of the population in Southern Africa (with the exception of South Africa) lacked access to electricity with relatively lower GDP and a higher population than North Africa (IRENA 2015). Africa's current electricity demand stands at 700TWh, with North African economies and South Africa accounting for more than $70 \%$.

The current energy needs of Africa are mainly met through a mix of biomass and fossil fuels. About $45 \%$ of Africa's total primary energy supply comes from biomass. Coal and natural gas account for about $14 \%$ and $16 \%$, respectively, while oil accounts for about $23 \%$. The share of renewables is almost negligible with hydropower, wind, and solar contributing approximately $2 \%$ of Africa's total primary energy supply in Africa (IEA 2019). A large percentage of energy demand in North Africa is met by oil and natural gas with a high potential for solar and wind energy, as shown in Fig. 1(a). The situation is similar in West Africa for coal and natural gas but with a major contribution from hydropower. Reports show that hydropower will continue to play an important role in all parts of Africa except perhaps in the north. Energy supply in Southern Africa is mainly from coal, while Central and East Africa are dominated by hydropower and wind energy. Considering the fundamental role of electricity in contemporary society and its cleanness and flexibility for a wide range of applications, gaining universal access to electricity easily and cost-effectively can be considered the single most critical energy-related goal for African policymakers. Figure 1(b) shows the electricity generation by various sources in Africa from 1999 to 2018 (IEA 2019). It is evident from the figure that there is a sharp increase in the total electricity generation from all sources. Before 2014, the contribution of renewable energy sources to Africa's electricity mix was very minimal apart from hydropower. However, solar and wind energy have realized a sharp growth from 2014.Similarly, electricity generation from geothermal and biofuels has also risen significantly, although at a much slower rate.

To scale up renewable energy development in Africa, states, policymakers, and stakeholders must create mechanisms that maximize socio-economic benefit. Many African countries have enacted clean energy policies that include tax benefits, public contributions, loans, and grants. Delegates from 46 countries in Africa, including 25 energy ministers, endorsed the Abu Dhabi Communiqué on Renewable Energy for Accelerating Africa's Development in 2011. Countries like South Africa, Ghana, Angola, Cameroon, Kenya, Ethiopia, and Rwanda, have national energy policies, although the frequency with which they are revised and applied consistently varies (on average 5-20 years). Kenya began implementing a feed-in tariff (FiT) scheme in 2008, requiring grid operators to guarantee priority acquisition, transmission, and deployment for wind, biomass, and hydropower generators and later revised these FiTs in 2010 to cover geothermal, solar, and biogas sources to reduce transaction costs and increase market competitiveness for private investors. In South Africa, the updated 2013 Integrated Resource Plan lays out a plan for diversifying the power mix, emphasizing low-carbon energy sources. Ghana also introduced a feed-in tariff by the Renewable Energy Act in 2011. In Mauritius, the government reduced co-generation taxes and provided other financial benefits to farmers who supplied bagasse for electricity generation to minimize dependence on imported oil. The regulations promoting co-generation have since made it easier and more appealing for suppliers to sell electricity to the grid under favourable rates and conditions (IEA 2014, IRENA 2015).

\section{Methodology}

\subsection{Data sources}

Bibliometric analysis employs mathematical and computational approaches to investigate the characteristics and trends of a document system by evaluating individual records as the research object (Du et al. 2014). The data in this study was collected from the Core Collection of Web of Science (WoS), compiled by Thomas Reuters and integrated in the ISI Web of Knowledge. WoS is a commonly used database that provides statistics on document types and languages, 
countries, institutions and authors, funding agencies, journals, and subject categories. It allows downloading of a full record and cited references of publications in text format for mapping and data analysis in other software. Academic publications on renewable energy in Africa from 1999-2020 were retrieved using the following indexes; Science Citation Index Expanded (SCI-EXPANDED), Social Sciences Citation Index (SSCI), and Arts and Humanities Citation Index $(\mathrm{A} \& \mathrm{HCl})$ on 26th March 2021. The keywords used to search the titles, abstracts, and keywords were "renewable energ*" and "Africa*." The search was refined by the document type set to "article," and the final results was used for further analysis in the VoSviewer software.

\subsection{Data analysis}

The VOSviewer software was used to analyse and visualize data downloaded from the Web of Science Core collection. This program is designed to identify patterns, frequencies, and trends in a large amount of information available in the literature. They have been integrated with co-citation, co-authorship, cooccurrence, mutual network analysis, and many other indicators for analyzing collaborations and links. Moreover, they support databases from China National Knowledge Infrastructure (CNKI), Chinese Social Sciences Citation Index (CSSCII), Scopus, and Web of Science. The academic influence of countries, organizations, institutions, and authors on the subject was analysed using the following indicators: total citations (TC), h-index, and impact factor. The h-index and impact factor indicators are a good measure of authors, journals, or research papers' performance. Hirsch's h-index was introduced as a reliable criterion for assessing the cumulative impact and value of an individual's scientific performance, and it has the advantage of being empirical (Hirsch 2005). In this context, an individual is linked to publications and may be an author, institution, country, journal, etc. The h-index denotes a period over which h of an individual's articles have been cited at least h times (Braun et al. 2006). Eugene Garfield also proposed the impact factor as a measure for journals in 1955. It represents the cumulative number to citations of papers published by this source over a two-year span (Amin \&Mabe 2004, Garfield 2006). Since it shows a clear association with the content of the articles written in a journal, IF is regarded as a significant index for assessing scholars and the influence of an article. In this study, the impact factor was obtained from JCR 2019 edition.

\section{Results}

\subsection{General characteristics of documents}

The search generated 1585 publications, out of which 1037 were articles representing $65.426 \%$, and the remaining document types were proceedings, reviews, editorial materials, news items, etc. Articles normally carry the trends and development of research; therefore, this study focused only on articles for further analysis. About $99.685 \%$ of all the articles were published in English, with the remaining $0.315 \%$ representing French, Russian, and Turkish. The total number of citations and average citations per document were 14,822 and 14.16, respectively. The trends in the number of articles and total citations from the WoS Core Collection during 1999-2002 are shown in Fig. 3. The number of publications has increased from 2009 with a few fluctuations but took a sharp and steady rise from 2017. The growth rate from 2016 to 2020 was $200 \%$. Within the last five years, the articles accounted for $72.13 \%$ of the total publications, with an average annual publication volume of 149.6 articles. This shows how much researchers have recently gained interest in renewable energy in Africa, especially in the last five years.

\subsection{Distribution of journals and subject categories}

The 1037 articles related to renewable energy in Africa from 1999 to 2020 were published in 310 journals. Only 15 journals (4.94\%) contained more than ten articles. The performance of the top 20 most productive journals containing about $53.4 \%$ of the articles is shown in Table 1 . The three topmost journals in terms of the number of publications were Energy Policy, Renewable Energy, and Journal of Energy in Southern Africa. However, the academic influence of the Journal of Energy in Southern Africa in terms of total citations, h-index, and impact factor (IF) is relatively lower than that of most of the other journals. The number of total citations is consistent with the $\mathrm{h}$-index values for most of the journals, i.e. journals with a higher number of citations tend to have relatively higher h-index values and vice versa. Applied Energy, which has the highest IF of 8.848, ranks 10th in terms of the number of publications and has an h-index of 12. It is worth noting that the African Journals have relatively low influence in terms of total citations, IF, and h-index. Additionally, some journal titles indicate the types of renewable energy with the most interest and the performance of some geographical locations. For instance, "Solar Energy" and "Biomass \& Bioenergy," also "Journal of Energy in Southern Africa."

The field of renewable energy is fast advancing, and research has demonstrated significant shifts into numerous disciplines. A total of 81 subject categories were covered in all the articles from WoS Core Collection. Figure 4 shows the distribution of the top 10 subject categories with respect to the number of publications. Energy \& Fuels ranked first with 465 articles accounting for $31 \% \%$ of all the articles, followed by Environmental Sciences (20\%) and Green Sustainable Science Technology (14\%). This outcome could be attributed to the fact that Energy \& Fuels mainly involves the development, production, use, application, conversion, and management of non-renewable fuels (e.g., coal, petroleum, and gas) and renewable energy sources (e.g., solar, wind, biomass, geothermal, hydroelectric), except for nuclear energy and nuclear technology (Yaoyang \&Boeing 2013). Publications related to Economics, Engineering (Chemical and Environmental) also play a major role in renewable energy research in Africa.

\section{Table 1}

Performance of top 20 most productive journals 


\begin{tabular}{|c|c|c|c|c|}
\hline Source & NP & $\mathrm{TC}$ & h-index & IF \\
\hline Energy Policy & 86 & 2832 & 30 & 5.042 \\
\hline Renewable Energy & 66 & 1524 & 24 & 6.247 \\
\hline Journal of Energy in Southern Africa & 50 & 182 & 8 & 1.106 \\
\hline Environmental Science and Pollution Research & 45 & 507 & 14 & 3.306 \\
\hline Energy Research \& Social Science & 38 & 553 & 13 & 4.771 \\
\hline Energies & 35 & 250 & 9 & 2.702 \\
\hline Energy & 34 & 691 & 14 & 6.082 \\
\hline Journal of Cleaner Production & 31 & 746 & 15 & 7.246 \\
\hline Sustainability & 29 & 117 & 7 & 2.576 \\
\hline Applied Energy & 19 & 547 & 12 & 8.848 \\
\hline Science of The Total Environment & 18 & 765 & 12 & 6.551 \\
\hline Energy for Sustainable Development & 14 & 207 & 8 & 3.610 \\
\hline Energy Strategy Reviews & 12 & 88 & 6 & 3.895 \\
\hline Biomass \& Bioenergy & 11 & 279 & 7 & 3.551 \\
\hline Solar Energy & 11 & 243 & 8 & 4.608 \\
\hline Climate Policy & 9 & 35 & 4 & 4.011 \\
\hline Energy Reports & 9 & 68 & 4 & 3.595 \\
\hline Environmental Research Letters & 9 & 176 & 4 & 6.672 \\
\hline International Journal of Energy Sector Management & 9 & 26 & 3 & 0.900 \\
\hline African Journal of Science Technology Innovation \& Development & 8 & 5 & 2 & 0.208 \\
\hline
\end{tabular}

\subsection{Performance and cooperation analysis of countries, institutions, and authors}

\subsubsection{Countries}

Different countries have contributed to the study of renewable energy in Africa, and this study revealed a total of 106 countries from 1999 to 2020 . It is worth mentioning that the countries' ranking depends on the affiliation of the main author. Figure 5 shows the geographical distribution of all countries involved in studies on renewable energy in Africa. The performance of the 20 most productive countries is also displayed in Table 3 . The top 20 countries consist of nine countries from Europe, five from Africa, three Asian countries, and two from America. South Africa produced the highest number of publications (23.82\%). Also, it ranked first in terms of total citations and h-index, followed by the USA producing $11.86 \%$ and Germany with $10.61 \%$ of the total publications. The five African countries, including South Africa, Nigeria, Kenya, Tunisia, and Ghana, produced 247, 65, 29, 28, and 24 publications, respectively. Apart from South Africa, Nigeria and Tunisia had the most academically influential publications in Africa, with total citations of 621,636 , and h-index 15,13 respectively.

The table also shows the number of articles based on corresponding authors' countries used to analyse single-country publications (SCP) and multi-country publications (MCP). With the leading number of articles, South Africa had 149 SCP and 52 MCP with an MCP ratio of 0.259 . Austria obtained the highest MCP ratio of 0.714 with 10 out of 14 publications being MCP, while India had the lowest MCP ratio of 0.158 with only 2 out of 13 publications being MCP. The coauthorship study of countries was conducted by setting a threshold with a minimum number of 10 papers per country based on the complete counting process in VOSviewer, which resulted in 39 countries reaching the threshold. Figure 6 illustrates the cooperation network analysis between various countries. The colour represents the cluster to which the countries are assigned based on the frequency of their relations, the circle size represents the number of publications, and the line connecting the circles depicts connections. The thicker the lines connecting them, the stronger the link between the two countries is. This, therefore, shows that South Africa had the highest number of collaborative links with other countries. The three strongest amongst them are with the USA, UK and New Zealand with 19, 16 and 14 publications between them respectively. The collaboration between Nigeria and Turkey was also very prominent, with a total of 13 publications. Collaborations among various African countries were observed to be relatively low except between South Africa and Nigeria. Five major clusters were identified in the figure. The first cluster (red) was the largest, comprising South Africa, the USA, UK, Germany, Nigeria, etc. The second cluster (green) included countries like Ghana, Norway, and Kenya. The third cluster (purple) involved Belgium, Switzerland, Cameroon, and others.

\section{Table 2}

Performance of top 20 most productive countries 


\begin{tabular}{|c|c|c|c|c|c|c|c|}
\hline Country & NP & TC & h-index & $N P *$ & SCP & MCP & MCP-ratio \\
\hline South Africa & 247 & 2341 & 26 & 201 & 149 & 52 & 0.2587 \\
\hline USA & 123 & 1926 & 23 & 68 & 47 & 21 & 0.3088 \\
\hline Germany & 110 & 1895 & 23 & 85 & 50 & 35 & 0.4118 \\
\hline United Kingdom & 104 & 1599 & 21 & 84 & 46 & 38 & 0.4524 \\
\hline Peoples R China & 69 & 921 & 18 & 62 & 34 & 28 & 0.4516 \\
\hline Nigeria & 65 & 621 & 15 & 31 & 19 & 12 & 0.3871 \\
\hline Turkey & 52 & 1065 & 18 & 22 & 16 & 6 & 0.2727 \\
\hline Italy & 42 & 828 & 14 & 31 & 14 & 17 & 0.5484 \\
\hline Netherlands & 42 & 617 & 16 & 22 & 15 & 7 & 0.3182 \\
\hline France & 35 & 485 & 13 & 13 & 6 & 7 & 0.5385 \\
\hline Spain & 34 & 571 & 11 & 17 & 10 & 7 & 0.4118 \\
\hline Australia & 33 & 880 & 13 & 22 & 9 & 13 & 0.5909 \\
\hline Sweden & 32 & 528 & 12 & 21 & 13 & 8 & 0.3810 \\
\hline Austria & 29 & 372 & 12 & 14 & 4 & 10 & 0.7143 \\
\hline India & 29 & 435 & 11 & 13 & 11 & 2 & 0.1538 \\
\hline Kenya & 29 & 469 & 10 & 11 & 5 & 6 & 0.5455 \\
\hline Pakistan & 28 & 278 & 8 & 13 & 10 & 3 & 0.2308 \\
\hline Tunisia & 28 & 636 & 13 & 22 & 15 & 7 & 0.3182 \\
\hline Ghana & 24 & 471 & 12 & 14 & 9 & 5 & 0.3571 \\
\hline Canada & 22 & 196 & 7 & 8 & 5 & 3 & 0.3750 \\
\hline
\end{tabular}

\subsubsection{Institutions}

Information from authors' addresses indicated that they were affiliated with a total of 1183 institutions. About $30 \%$ of all the articles were associated with the top 20 institutions. Table 3 shows the impact and collaboration degree of the 20 most productive institutions. Among them, nine were from South Africa, four from Europe, two from Nigeria, and one from America, Ghana, New Zealand, and Tunisia. The three most productive institutions in all performance indicators (Univ. Cape Town, Univ. Pretoria, and Univ. Stellenbosch) are from South Africa. Univ. Johannesburg ranks 4th in the number of publications (22) but had a relatively low h-index of 5 . The table shows a strong correlation between total citations h-index, i.e., institutions with a higher number of citations have a relatively higher value of h-index. Even though Ghana Inst. Management Publ. Adm. produced the least number of articles among the top 20; it had a higher number of total citations and $h$-index than some institutions in the list, indicating the high influence of articles in the research field. The co-authorship study of organizations was conducted using the "organizations" unit from the download data and the complete counting process in the VoSviewer by setting a threshold for a minimum number of 7 papers per entity, which resulted in 32 organizations with only 26 having collaborations. The collaboration network of the various institutions is shown in Fig. 7. The number and thickness of the links in the figure indicate that; Univ. Cape Town had the highest degree of collaborations with other institutions, and the most prominent ones include Univ. Pretoria, Stellenbosch Univ. and Stockholm Environm. Inst. The strongest link can be seen between Stellenbosch Univ. in South Africa and Victoria Univ. Wellington in New Zealand with 13 publications between them. It was observed that most institutions had more domestic cooperation than multi-national cooperation. There are eight major clusters in the figure. The largest cluster (red) was led by Univ. Pretoria, and included Univ Stellenbosch and Covenant Univ.

\section{Table 3}

Performance of top 20 most productive institutions 


\begin{tabular}{|lllll|}
\hline Institutions & NP & TC & h-index & No. of collaborations* \\
\hline Univ Cape Town & 49 & 767 & 15 & 11 \\
\hline Univ Pretoria & 37 & 552 & 13 & 8 \\
\hline Univ Stellenbosch & 27 & 425 & 13 & 6 \\
\hline Univ Johannesburg & 22 & 134 & 5 & 6 \\
\hline CSIR & 17 & 217 & 8 & 7 \\
\hline Univ Sussex & 16 & 236 & 10 & 3 \\
\hline Victoria Univ Wellington & 14 & 58 & 5 & 4 \\
\hline Univ Kwazulu Natal & 13 & 63 & 4 & 0 \\
\hline Cent Univ Technol & 11 & 178 & 7 & 1 \\
\hline Univ Witwatersrand & 11 & 34 & 4 & 3 \\
\hline Univ Ibadan & 10 & 91 & 3 & 1 \\
\hline Eastern Mediterranean Univ & 9 & 265 & 6 & 2 \\
\hline Tshwane Univ Technol & 9 & 15 & 2 & 5 \\
\hline Univ Sfax & 9 & 104 & 4 & 0 \\
\hline Univ Utrecht & 9 & 159 & 6 & 2 \\
\hline Aarhus Univ & 8 & 129 & 6 & 1 \\
\hline Covenant Univ & 8 & 44 & 5 & 4 \\
\hline North West Univ & 7 & 242 & 6 & 1 \\
\hline Stanford Univ & 71 & 5 & 0 \\
\hline Ghana Inst Management Publ Adm & 73 & 3 & 0 \\
\hline Note: NP- number of publications, TC- total citations, *collaborations among the top 30 & \\
\hline
\end{tabular}

\subsubsection{Authors}

This study revealed 2716 authors from the WoS Core Collection in relation to research on renewable energy in Africa from 1999 to 2020 . The ten most productive authors are displayed in Table 4 based on their number of publications, total citations, h-index, and degree of collaboration. The most productive authors are dominantly Africans from South Africa and Ghana, with the remaining authors from Europe, particularly Turkey, Sweden, and Germany. Brent AC. produced $2.4 \%$ of the 1,037 articles and had the highest ranking in terms of the number of publications and h-index, followed by Sarkodie $S A$ and Kusakana $K$, who produced ten publications each but with different numbers of total citations and h-index. Sarkodie $S A$ had the highest number of citations among the ten most productive authors, with a relatively high h-index indicating higher academic influence. The co-authorship study of authors was conducted using the "authors" unit from the download data and the complete counting process in the VoSviewer by setting a threshold for a minimum number of 3 papers per entity, which resulted in 35 authors with only 28 having collaborations. The collaboration network of authors is shown in Fig. 8. Observations that emerge from the study of the collaboration networks of the most relevant authors reveal that their collaborations were mostly centred on colleagues from the same groups or organizations. For instance, Brent $A C$ and Musango JK, who had the highest number of joint papers (7) represented by the thickest line connecting them, are affiliated with Stellenbosch University in South Africa. Brent AC and Musango JK, who are both prolific authors in this field, have mostly focused their research in South Africa and have given particular attention to solar energy, among the other energy sources. The relationship among Bodis $K$, Szabo $S$, and Moner-Girona $M$ is also worth noticing. The three authors all belong to the European Commission Joint Research Centre and have also centred their research on solar energy and universal access to electricity. The second strongest link is found between Ikejemba ECX and Schuur $P$ with five joint publications. Sarkodie SA also collaborated with Adams S, Bekun FV, and Asongu SA.

\section{Table 4}

Performance of top 10 most productive authors 


\begin{tabular}{|lccll|}
\hline Author & NP & TC & h-index & No. of collaborations* \\
\hline Brent AC & 25 & 331 & 10 & 4 \\
\hline Kusakana K & 10 & 164 & 6 & 1 \\
\hline Sarkodie SA & 10 & 557 & 7 & 3 \\
\hline Trieb F & 8 & 379 & 7 & 0 \\
\hline Adams S & 7 & 238 & 5 & 1 \\
\hline Musango JK & 7 & 102 & 5 & 1 \\
\hline Ozturk I & 7 & 273 & 5 & 3 \\
\hline Ahlborg H & 6 & 214 & 4 & 0 \\
\hline Asongu SA & 6 & 134 & 4 & 1 \\
\hline Baker L & 6 & 92 & 4 & 2 \\
\hline Note: NP- number of publications, TC- total citations *collaborations among the top 30 \\
\hline
\end{tabular}

\subsection{Author keyword analysis}

Author keywords mostly define the main idea of a research field, and they are used to evaluate trends in a particular field of study (Chen et al. 2016). The 1,037 articles in this study produced a total of 2,790 author keywords. About 2,266 (81.2\%) of the total keywords appeared only once, while 524 accounting for $18.8 \%$, appeared more than once, indicating huge diversity in research topics. The top 50 (1.8\%) most frequently used keywords accounted for $48.6 \%$ of the total keyword occurrences. Table $\mathbf{5}$ shows a list of the top 20 author keywords with their frequencies of occurrence. 'Renewable energy'and 'Africa' had the highest occurrences representing $10.7 \%$ and $3.9 \%$, respectively. This outcome is not surprising as the search term for this research was based on these two keywords. 'South Africa'stands out as the most represented country in the figure, with 90 occurrences accounting for 3 . $2 \%$ of the total author keywords and the third most frequently used keyword. This output supports the evidence that South Africa is the most studied region in this field, as shown in the previous analysis. The most prominent keyword in terms of renewable energy sources is 'solar energy with 36 total occurrences. Research on renewable energy in Africa is also highly linked to economic growth, rural electrification, and climate change mitigation.

The evaluation of the co-occurrence of author keywords was conducted by establishing a threshold with a minimum number of 10 occurrences per keyword, which resulted in 44 author keywords reaching the threshold, based on the "author keywords" unit from the download data and the complete counting process in the VOSviewer. Figure 9 illustrates a network map of the most frequently used author keywords in this field from 1999 to 2020 . The different colours in the figure represent different clusters to which the author keywords are assigned based on the frequency of their associations. The circle size represents the number of publications, and the line connecting the circles represents links between keywords. The analysis provided five major clusters. The first cluster (red) was led by 'renewable energy and includes other keywords like 'energy,' 'energy access,' 'solar energy,' 'wind energy,' 'biogas,' 'Nigeria,'and 'North Africa.' The second cluster (green) was focused more on 'climate change' and 'sustainable development.' It was highly linked with keywords such as 'Africa,' 'environment,' 'energy security,' 'development,' hydropower' and 'China.' The third cluster (blue) was led by 'South Africa' and included other keywords like 'energy efficiency, 'energy policy,' 'energy transition,' 'electricity' 'optimization' and 'Morocco.' The fourth cluster (yellow) also was concentrated on 'economic growth,'and 'CO 2 emissions' with related keywords like 'financial development,' 'renewable energy consumption,' 'ecological footprint' and 'BRICS (Brazil, Russia, India, China, and South Africa).' The final cluster (purple) included 'rural electrification,' 'sub-Saharan Africa,' 'developing countries,' 'Kenya,'and 'bioenergy.'

Table 6 shows the development of keywords in five continental regions based on the top 50 most productive countries in four different time stages. The 10 most frequently used keywords were chosen for each region. The purpose is to study the dynamism of literature in different regions and the relationship among these studies. About $72 \%$ of all the publications occurred from 2016 to 2020; hence the highest number of keywords occurred in this period. However, only $1.5 \%$ of articles were published from 1999 to 2004 , with a scanty number of keywords shown in only three out of the five regions. 'South Africa' maintained a steady position as the second most frequently used keyword from 2005 to 2020 in articles published in Africa, indicating consistent focus over a long period. The most studied renewable energy source in Africa transitioned from 'bioenergy during the first decade to 'solar energy' in the second decade.

Moreover, articles published in Africa began to pay more attention to environmental impacts (particularly $\mathrm{CO}_{2}$ emissions and climate change) in the last two stages. The articles published outside Africa showed relatively more diversity in the keywords over different time stages. The African-European partnership adopted in 2007 was one of the main research motivations in this area in Europe from 2005 to 2010. The Africa-EU Energy Partnership (AEEP) was adopted by 80 African and European Heads of State and Government at the 2007 Lisbon Summit as a long-term framework for strategic partnership geared towards exchanging ideas, setting political priorities, and developing joint programs on key energy issues. Most of the studies in Europe focused on more specific topics based on author keywords like 'desalination,' 'castor bean' among others. Articles published in Europe and America shared more keywords between them, such as 'HVDC transmission' and 'African electricity infrastructure' in the first stage, indicating the trend of such topics during this period. During the previous two decades, the power crisis in Africa has been a major concern and has contributed massively to most of the slow economic development of most parts of the continent. About 39 Sub-Saharan African countries have lost up to 2 percentage points in yearly real per capita GDP growth due to power outages. A study from the early 2000s discusses the World Bank's engagement in African electricity infrastructure and the possibilities for establishing Africa's unified power system by reviewing feasibility studies of high voltage direct current (HVDC) transmission from the Democratic Republic of Congo to Egypt and other studies to South Africa and Europe. According to this paper, over 70 projects in 26 Sub-Saharan African nations have been funded by the World Bank with the broad aim of poverty alleviation and improving economic growth. HVDC transmission was found to be the optimal solution for interconnections between

Page $8 / 23$ 
regions due to long distances and other technological issues. The profitability of the HVDC link between the central, northern, and eastern regions of Africa to transmit hydroelectric electricity from the Inga project to Egypt, Sudan, the Central African Republic, and Chad was demonstrated in pre-feasibility studies (Hammons et al. 2000). Based on the frequency of keywords like 'environmental sustainability, 'climate change,'and 'energy policies,'it was deduced that studies from the Americas concentrated more on management, environmental impacts, and policy development of renewable energy in Africa during the last three stages. Publications on renewable energy in Africa started from 2005 in Asia and 2011 in Oceania. Similar to articles published in Africa, the first two stages in Asia focused on 'bioenergy' and transitioned to 'solar energy during the last stage. More emphasis was placed on the economic growth and development of this field in articles from Asia. Studies from Oceania focused more on case studies using the 'Environmental Kuznets Curve (EKC) hypothesis' and 'multi-criteria decision methods.'

\section{Table 5}

Number of occurrences for the 20 most frequently used author keywords

\begin{tabular}{|llllll|}
\hline Rank & Keywords & Occurrences & Rank & Keywords & Occurrences \\
\hline 1 & Renewable energy & 298 & 11 & Sustainability & 30 \\
\hline 2 & Africa & 108 & 12 & Energy & 28 \\
\hline 3 & South Africa & 90 & 13 & Renewable energy consumption & 25 \\
\hline 4 & Economic growth & 53 & 14 & Electricity & 24 \\
\hline 5 & Sub-Saharan Africa & 49 & 15 & Energy consumption & 22 \\
\hline 6 & CO 2 emissions & 41 & 16 & Energy transition & 20 \\
\hline 7 & Rural electrification & 37 & 17 & Wind energy & 20 \\
\hline 8 & Solar energy & 36 & 18 & BRICS & 18 \\
\hline 9 & Climate change & 33 & 19 & Carbon emissions & 17 \\
\hline 10 & Sustainable development & 33 & 20 & Energy efficiency & 17 \\
\hline
\end{tabular}

\section{Table 6}

The development of keywords related to renewable energy in Africa in five continental regions 


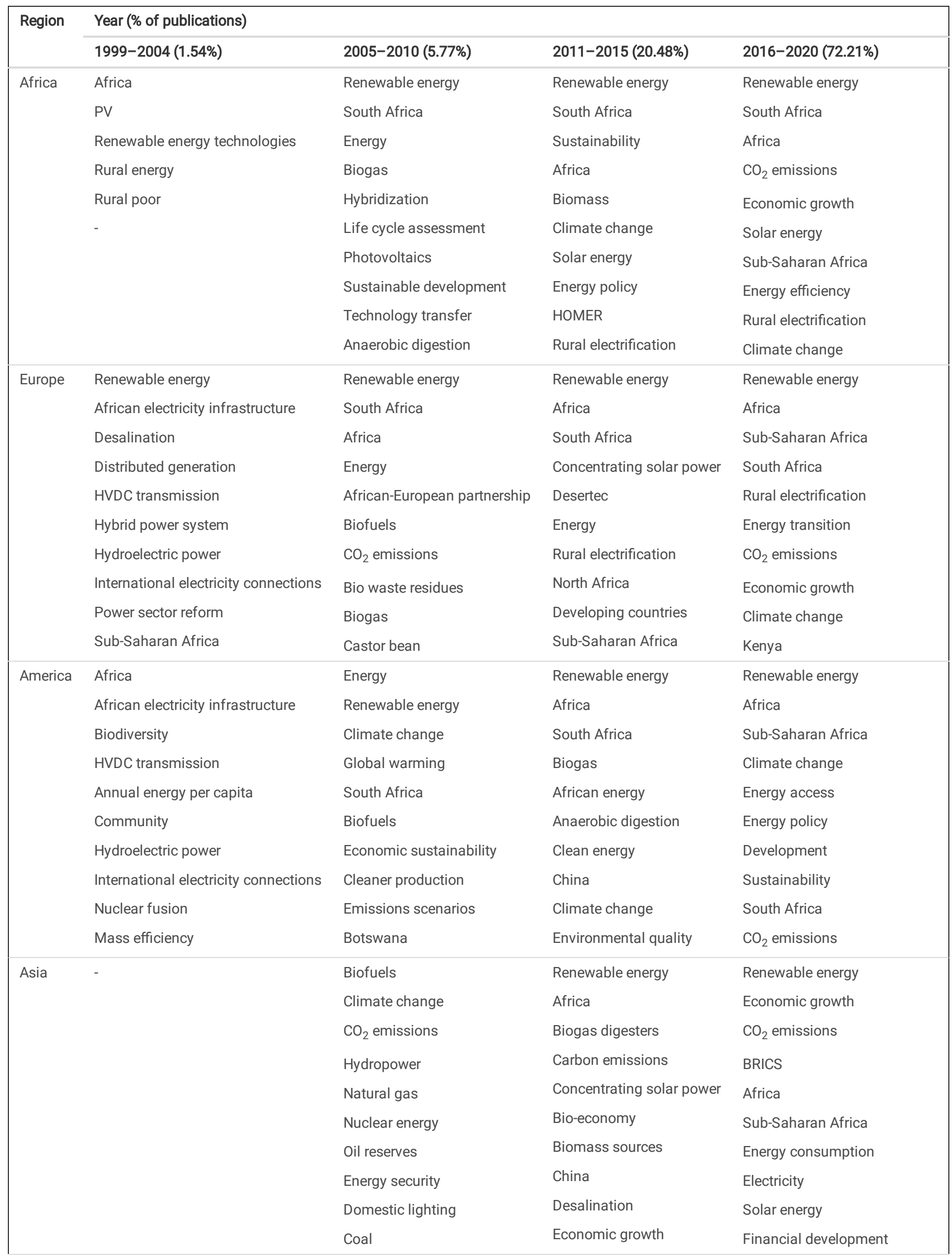




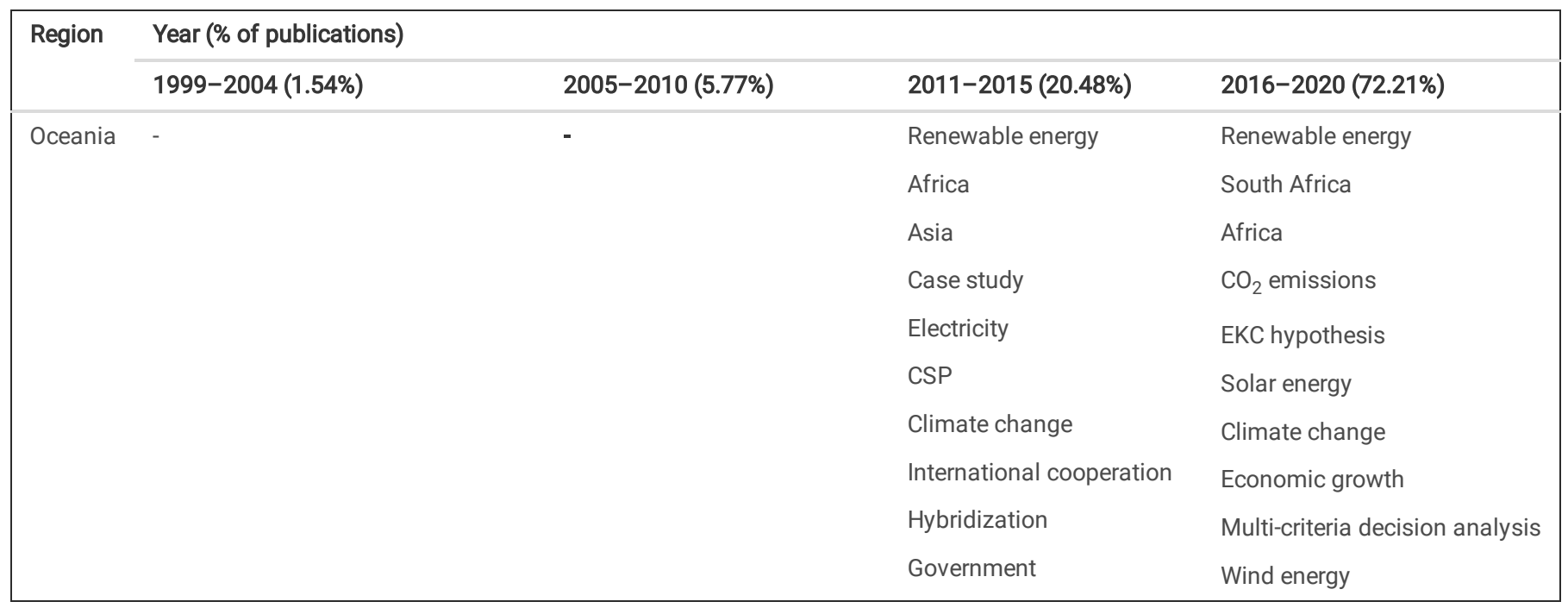

\subsection{Development of research topics and classifications from keyword analysis}

In order to understand the dynamics of topics over time, this study divided the years under review, i.e., 1999-2020, into four stages. The development of the top 20 keywords in each stage is shown in Fig. 10. All the keywords apart from 'renewable energy', 'South Africa', 'Africa' and 'energy' all appeared after the second stage, i.e., from 2011. This shows that topics related to this research field began to expand around this time to include more specific terms. The use of broader terms generally began to decline to accommodate for more detailed topics; for instance, the keyword 'climate change' was more prominent in the third stage but was overtaken by ' $\mathrm{CO}_{2}$ emissions' in the last stage. During the third stage, keywords like 'rural electrification,' 'solar energy,' sustainability,' 'electricity,'

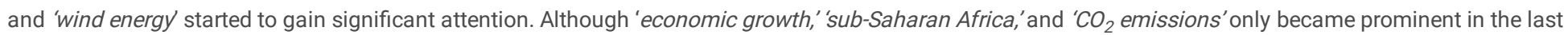
stage, they have gained a high degree of attention to be considered as research hotspots.

The author keywords that appeared more than three times were collected and classified under six major categories: Energy source, Environment, Purpose, Study area, Technology, and Method. The keywords under each category were analysed and presented in Fig. 11. The domain classification was done to reveal the dominant topics and the relations of categories. In terms of energy sources, 'solar energy' was the most studied topic, followed by 'wind energy,' 'hydropower' and 'bioenergy." Nuclear' and 'geothermal energy' were the least studied sources. According to the International Renewable Energy Agency (IRENA), Africa's renewable energy has the capacity to reach $310 \mathrm{GW}$ by 2030 , putting the region at the forefront of renewable energy output worldwide considering the almost unlimited potential of solar capacity (10 TW), hydro (350 GW), wind (110 GW), and geothermal energy sources (15 GW) (Hafner et al. 2018). In the past, hydropower has been Africa's most widely used renewable energy source. Hydropower output has, however, become more unreliable as a result of climate change. Based on the current BP Statistical Review (BP 2020), the development of solar and wind energy in Africa has been on the rapid rise since 2014 compared to other renewable energy sources. Wind and solar power have just lately become commercially feasible, and while they are both weather-dependent, Africa's solar energy potential, in particular, remains high owing to the continent's position. This realization has motivated more recent studies in this research field towards the direction of solar energy. Furthermore, solar energy is one of the energy sources with the highest potential in South Africa, which also has the top-ranking solar market in Africa. Since most studies in this field come from South Africa, it could be another reason for the proliferation of literature on solar energy.

Not surprisingly, the three most frequently used keywords under 'Technology,' namely 'concentrated solar power,' 'desalination,'and 'photovoltaic,' are all directly or indirectly related to solar energy. Photovoltaic (PV) and concentrated solar power (CSP), often known as solar thermal energy, are two well-known methods for generating electrical energy from solar radiation. Solar power is generated via concentrated solar power systems, which use mirrors or lenses to focus a huge area of sunlight onto a receiver. When concentrated light is converted to heat (solar thermal energy), electricity is created, which powers a heat engine (often a steam turbine) connected to an electrical power generator (Law et al. 2014). The Ouarzazate Solar Power Station in Morocco, which combines trough and tower technologies, is one of the largest concentrated solar plants globally for a total of $510 \mathrm{MW}$ with several hours of energy storage (Boisgibault \&Al Kabbani 2020). On the other hand, PV uses the photoelectric effect to generate power. Photovoltaic panels normally use silicon to directly convert solar radiation into electrical energy (Pegels 2010). South Africa is home to the majority of the largest solar PV plants in Africa. The $96 \mathrm{MW}$ Jasper Solar Energy Project, which has the capacity to power up to 80000 homes, is one of the largest operational plants on the continent (SolarReserve 2015). Over the last five years, the cost of solar PV has decreased significantly, mostly due to considerable price reductions in modules, owing to enhanced research \& development, and more market participants. The estimates that more than 100 million additional consumers worldwide are expected to switch to solar over the next 20 years as the price of rooftop solar is almost equal to that of coal-fired electricity (Africa Report 2015). In terms of total installed capacity in Africa, solar PV is way ahead of CSP due to the reduced solar PV prices (BP 2020). However, CSP penetration in the African market is promising since it is anticipated to see more substantial cost reductions in the future coupled with its greatest advantage over solar PV, i.e., the ability to store energy, especially when power is most needed on the grid system (Moyo et al. 2017). Integration of renewable energy sources like solar, wind, and geothermal energy with desalination systems offers excellent potential for addressing water shortages and might be a feasible solution to climate change and water scarcity concerns (Renewable Desalination 2010). In order to generate freshwater, these renewable energy sources can be combined with thermal distillation processes like multi-stage flash distillation, multiple-effect distillation, and vapor-compression evaporation or membrane desalination technologies such as reverse osmosis, electrodialysis, and membrane distillation (Shatat \&Riffat 2012). Solar energy has been found as a feasible energy source for generating freshwater from salty water, 
particularly in several African countries, which are located in semi-arid and sunny climates (Al-Kharabsheh 2003). Therefore, several studies in this field have been directed towards solar desalination as compared to the other renewable energy sources.

'Optimization' appeared most frequently as the most commonly used research method in this field, followed by 'HOMER,' a software application for designing and evaluating options for off-grid and on-grid power systems for remote, stand-alone, and distributed generation applications. 'Life-cycle assessment,' 'Environmental Kuznets Curve, and 'scenario analysis' are other popular evaluation methods in this field. Life cycle assessment (LCA) analyses the environmental impacts of systems or products from the extraction and supply of materials and fuels, to the manufacturing and operation of the studied items, to their disposal/recycling (i.e., from cradle to grave) (ISO 1997). LCA has been widely applied in renewable energy research to analyse the environmental effect of energy generation from various sources, allowing producers to make more informed decisions about environmental protection (Góralczyk 2003). Since the early 1990s, the EKC hypothesis has been the most popular explanation for the relationship between economic development and environmental degradation. According to the EKC theory, economic activity and environmental deterioration have an inverted U-shaped connection (Demissew Beyene \&Kotosz 2020, Halkos \&Managi 2016, Shafik \&Bandyopadhyay 1992). A number of studies in Africa have investigated at the validity of EKC, using different econometric approaches and concentrating on different areas (Ben Jebli et al. 2015, Kohler 2013, Shahbaz et al. 2015).

With respect to the 'Purpose' category, research themes were focused mainly on 'economic growth,' 'rural electrification,'and 'sustainable development.'Energy is vital for economic growth, and a lack of appropriate electricity generation is undoubtedly a barrier to sustainable development. Sustainable development can be defined as "development that meets the needs of the present without compromising the ability of future generations to meet their own needs" (Brundtland \&Khalid 1987). Some development has recently been made on providing a standardized set of energy indicators for sustainable development considering the economy, society, and environmental components. These quantitative indicators for comparing the sustainability of renewable energy technologies include the price of generated power, GHG emissions, renewable energy availability, energy conversion efficiency, land needs, and water usage (Varun et al. 2010). A comprehensive overview of renewable energy and sustainable development in West Africa by Gyamfi et al. (2018) indicated that renewables in West Africa have the prospect to help achieve the SDGs, as evidenced by the potential of renewable energy resources in the region. The energy sector of Africa is critical to the continent's economic growth and development, but it is also one of the world's least understood energy systems. Several studies have revealed a positive and significant impact of renewable energy sources like solar, wind, and hydropower on economic growth (Maji 2015, Sbia et al. 2014, Simsek \&Simsek 2013). However, when dirty and inefficient sources such as burning wood biomass are exploited, renewable energy consumption can hinder economic growth by reducing productivity (Maji et al. 2019). As the bulk of Africa's population still lives in rural regions, the necessity of supplying stable and clean energy to rural areas cannot be overstated. In recent years, governments and policymakers have been paying much attention to renewable energy alternatives like solar energy (both photovoltaic and thermal), wind turbines, and micro-hydropower for generating electricity as viable options for improving the lives of the rural population. Rural electrification is a critical initiative for improving a country's rural areas' socio-economic situation as studies have emphasized its role in fostering economic growth and livelihood security by supplying electricity as a productive input in agriculture and rural industries, as well as assisting in the improvement of overall quality of life (Nouni et al. 2008).

The most studied keywords related to environmental impacts include $\mathrm{CO}_{2}$ emissions, climate change, and carbon emissions. The United Nations has identified Africa as the most vulnerable continent to the consequences of climate change due to population increase and its associated human activities, overreliance on subsistence farming, limited ability to adapt to change, and imminent water problems. This shows the urgency of renewable energy transition in terms of environmental emissions, particularly $\mathrm{CO}_{2}$ emissions in climate change mitigation in recent years. To combat the problem of $\mathrm{CO}_{2}$ emissions from fossil fuel energy sources, several studies in Africa have highlighted the importance of increasing the usage of renewable energy in place of fossil fuel energy (Adewuyi \&Awodumi 2017, Maji 2015, Ozturk \&Bilgili 2015). The various studies have found ample evidence to support the fact that renewable energy sources, such as solar, wind, and hydropower, do not contribute to $\mathrm{CO}_{2}$ emissions during the production chain, and unlike fossil fuel energy, the amount of renewable energy sources on the earth's surface is not limited.

Based on the frequency of author keywords, South Africa was found to be the most commonly studied area, followed by Nigeria and Kenya.

\subsection{Citation analysis}

While there are many studies in a research field, the relatively small number of highly cited articles could represent the research direction of follow-on publications (Schwartz et al. 2005). Table 7 shows the main information about the ten most cited articles in this field of study from 1999 to 2020 . Eight of these highly cited articles came from Europe. Forty percent of the ten articles were published in Energy Policy. The most cited article is titled "Energy consumption, pollutant emissions and economic growth in South Africa," with 313 citations (Menyah \&Wolde-Rufael 2010). The purpose of this work was to examine the relationship between economic growth, energy use, and pollutant emissions in a multivariate context, with labour and capital as additional variables. One of the key findings from this study suggests that, by introducing energy alternatives to coal, the country's primary source of $\mathrm{CO}_{2}$ emissions, it is possible to satisfy its energy needs while still reducing $\mathrm{CO}_{2}$ emissions. Furthermore, improving energy efficiency and using the country's renewable energy resources could be promising choices for addressing the country's major energy and environmental challenges (Menyah \&Wolde-Rufael 2010). “Cleaner energy for sustainable future" by Dovi et al. (2009) with 205 citations was the second most cited document in this field. This paper is a part of a special issue that aims to identify policies that will help promote and disseminate technologies and management techniques that ensure global transition toward more sustainable societies. To achieve this goal, papers were gathered from approximately 100 contributors from Africa, North America, Asia, and Europe, representing 28 countries. It was found that these papers address several issues related to global climate change, as well as the effects that the choices of various energy sources and investments in energy conservation in manufacturing and consumption have on societal sustainability (Dovì et al. 2009). Three of the ten most cited articles concentrated specifically on solar energy (Shatat et al. 2013, Szabó et al. 2011, Viebahn et al. 2011). It is also worth noting that economic factors such as foreign investments and the economic feasibility of renewable energy technologies play a key role in this field of research. South Africa was the only outstanding country represented in the titles of two of the most cited articles (Deichmann et al. 2011, Menyah \&Wolde-Rufael 2010), which further supports previous analysis that it is the country with the highest academic performance in this area of study. 
Top 10 most cited articles

\begin{tabular}{|c|c|c|c|c|c|}
\hline Rank & Paper Title & Journal & $\begin{array}{l}\text { Times } \\
\text { Cited }\end{array}$ & Country & Ref. \\
\hline 1 & Energy consumption, pollutant emissions and economic growth in South Africa & Energy Economics & 313 & UK & $\begin{array}{l}\text { (Menyah } \\
\text { \&Wolde- } \\
\text { Rufael } \\
\text { 2010) }\end{array}$ \\
\hline 2 & Cleaner energy for sustainable future & $\begin{array}{l}\text { Journal of Cleaner } \\
\text { Production }\end{array}$ & 205 & Italy & $\begin{array}{l}\text { (Dovì et al. } \\
\text { 2009) }\end{array}$ \\
\hline 3 & $\begin{array}{l}\text { Liquid Organic Hydrogen Carriers as an efficient vector for the transport and storage } \\
\text { of renewable energy }\end{array}$ & $\begin{array}{l}\text { International } \\
\text { Journal of } \\
\text { Hydrogen Energy }\end{array}$ & 192 & Germany & $\begin{array}{l}\text { (Teichmann } \\
\text { et al. 2012) }\end{array}$ \\
\hline 4 & $\begin{array}{l}\text { Effect of foreign direct investments, economic development and energy consumption } \\
\text { on greenhouse gas emissions in developing countries }\end{array}$ & $\begin{array}{l}\text { Science of the } \\
\text { Total Environment }\end{array}$ & 183 & Australia & $\begin{array}{l}\text { (Sarkodie } \\
\& \text { Strezov } \\
2019)\end{array}$ \\
\hline 5 & Opportunities for solar water desalination worldwide: Review & $\begin{array}{l}\text { Sustainable Cities } \\
\text { and Society }\end{array}$ & 148 & UK & $\begin{array}{l}\text { (Shatat et } \\
\text { al. 2013) }\end{array}$ \\
\hline 6 & $\begin{array}{l}\text { The potential role of concentrated solar power (CSP) in Africa and Europe-A dynamic } \\
\text { assessment of technology development, cost development and life cycle inventories } \\
\text { until } 2050\end{array}$ & Energy Policy & 136 & Germany & $\begin{array}{l}\text { (Viebahn et } \\
\text { al. 2011) }\end{array}$ \\
\hline 7 & The economics of renewable energy expansion in rural Sub-Saharan Africa & Energy Policy & 133 & USA & $\begin{array}{l}\text { (Deichmann } \\
\text { et al. 2011) }\end{array}$ \\
\hline 8 & Renewable energy in South Africa: Potentials, barriers and options for support & Energy Policy & 132 & Germany & $\begin{array}{l}\text { (Pegels } \\
\text { 2010) }\end{array}$ \\
\hline 9 & Determinants of renewable energy growth: A global sample analysis & Energy Policy & 128 & Scotland & $\begin{array}{l}\text { (Aguirre } \\
\text { \&lbikunle } \\
\text { 2014) }\end{array}$ \\
\hline 10 & $\begin{array}{l}\text { Energy solutions in rural Africa: mapping electrification costs of distributed solar and } \\
\text { diesel generation versus grid extension }\end{array}$ & $\begin{array}{l}\text { Environmental } \\
\text { Research Letters }\end{array}$ & 126 & Italy & $\begin{array}{l}\text { (Szabó et } \\
\text { al. 2011) }\end{array}$ \\
\hline
\end{tabular}

Co-citation refers to the number of times two documents are cited together by a third document (Small 1973). The co-citation analysis of cited references was conducted using the "cited references" unit from the download data and the complete counting process in the VoSviewer by setting a threshold for a minimum number of 25 citations per reference, which resulted in 31 cited references. Figure 9 shows the co-citation network among the top 31 most cited references. The colour indicates the cluster to which the cited references are attributed according to the strength of their relationships, the size of the circle relates to the number of citations, and the line between the circles represents links. The strongest relationship is seen between Levin et al. (2002) and Im \&Pesaran (2003). There were two major clusters identified. The cluster (red) was led by Levin et al. (2002) and included other references that mostly focus on the panel unit root test in the power parity hypothesis. Most of the documents in this cluster were published in the Journal of Econometrics and other economics-related journals. The most co-cited reference with 54 co-citations in this cluster is titled 'Unit root tests in panel data: asymptotic and finite-sample properties' and was published in the Journal of Econometrics. In this paper, the authors designed a method to test the null hypothesis that each time series comprises a unit root against the alternative hypothesis that each time series is stationary using pooled cross-section time-series data (Levin et al. 2002). The study of integrated series in panel data has progressed significantly since the pioneering studies of Levin and others (Quah 1994), and panel unit root tests have been applied to various disciplines. Several studies have since applied panel unit root test in this field of research from different perspectives, particularly for determining the relationships among energy consumption, $\mathrm{CO}_{2}$ emission, and economic growth and mostly focusing on the Sub-Saharan African region (Adams et al. 2016, Esso \&Keho 2016, Oluoch et al. 2021). The references in the other cluster (green) were led by Pegels (2010) with 48 co-citations. This document is titled 'Renewable energy in South Africa: Potentials, barriers and options for support' and was published in Energy policy. According to this paper, the main barrier to renewable energy development in South Africa is focused on the economics of renewable energy technologies, particularly their expense and risk mechanisms, which are two important considerations in investment planning (Pegels 2010). The majority of documents in this cluster were published in Energy Policy journal.

\section{Research Hotspots And Recommendations For Future Research}

The commitment of nations, including most African countries, to the Kyoto Protocol to mitigate climate change by reducing harmful emissions has directed renewable energy studies in Africa to focus mainly on ' $\mathrm{CO}_{2}$ emissions' and 'climate change.' Furthermore, Africa is considered the most vulnerable region to suffer from the impending dangers of climate change from extreme weather events and consequent adverse health effects to drastic changes in water availability. Sustainable development has also become one of the main goals that drive research in this field of study.

South Africa's share in global warming has attracted urgent attention since 2005 as its per capita emissions of 9 tonnes $\mathrm{CO}_{2}$ e per person rose above the global average of 5.8 tonnes and six times more than the average of sub-Saharan Africa with1.4 tonnes (World Resource Initiative 2009). This issue, coupled

Page 13/23 
with insufficient energy supply (about $24 \%$ of households lacked access to electricity in 2004), triggered the government to target universal access by 2012. This motive could explain the rapid rise of research in the last two decades to find alternative energy sources to boost energy security and reduce greenhouse gas emissions. The topic development in the last five years also showed that research has widely extended to other sub-Saharan African countries, including mostly Nigeria, Kenya, and Ghana. Future studies in this area could involve more African countries, and collaborations between the countries could be greatly improved to promote balance in developing renewable energy in Africa.

The BP Statistical Review of World Energy (BP 2020) indicated that Africa's solar and wind energy development had seen a sharp increase since 2014. Electricity generation from solar PV increased from 313 GWh in 2013 to 1529 GWh in 2014 and 5561GWh to 8555 GWh by wind energy. Solar energy is one of the renewable energy sources with the highest potential in Africa, especially in South Africa and most parts of North Africa; therefore, the topic has received much attention over the years. Technologies for the production of electrical energy have been mainly centered on photovoltaics and concentrated solar power, which has continued to receive a lot of attention over the last five years. Renewable energy sources like nuclear and geothermal energy received less attention over the years and must be considered for future research. Geothermal energy, like wind and solar power, has the potential to help Africa's energy sector transition away from hydropower dependence and toward drought resilience. Studies have shown that the geologically active region of the Great Rift Valley, which stretches from Djibouti to Mozambique, is one of the most crucial regions of the world with enormous potential for geothermal energy (Karekezi \&Kithyoma 2003, Younger 2014). Nuclear power has the potential to contribute significantly to alleviating Africa's power problem since it can supply lowcarbon electricity at a large scale, reliably, and without intermittency and especially, considering the continent's substantial uranium reserves (World Nuclear Association 2013). However, the relative shortage of technical expertise and absence of nuclear safety culture coupled with the high initial investment costs of facilities stand to be a major barrier to the development of nuclear energy in Africa (Kessides 2014). Therefore, more studies are needed to investigate these factors, among many others, to identify more sustainable ways of nuclear energy development in Africa.

Sub-Saharan Africa had the lowest share of rural electrification globally at only $14 \%$ as of 2016 , which has greatly affected socio-economic development in this region (Ahlborg et al. 2015, World Bank 2015). Moreover, the vast disparity between access to electricity in the rural and urban areas is 3.5 times greater in sub-Saharan Africa than anywhere else (Mandelli et al. 2014). 'Rural electrification' has become one of the hot issues directly linked to renewable energy in the past decade. Topics like; hybrid energy systems, micro-grid, and optimization are closely related to rural electrification in supplying electricity to remote rural areas which are not connected to the national grid. Also, two of the ten most cited papers talked about "The economics of renewable energy expansion in rural Sub-Saharan Africa" and "Energy solutions in rural Africa: mapping electrification costs of distributed solar and diesel generation versus grid extension" (Deichmann et al. 2011, Szabó et al. 2011).

\section{Conclusion}

Data gathered from the Web of Science Core collection were analysed using VOSviewer software to map characteristics of research output on renewable energy in Africa from 1999 to 2020. The annual production of publications, performance, and contributions of research entities and research hotspots was determined through bibliometrics. This study revealed that growth in the number of publications and total citations was very slow and unsteady in the first decade but started to rise steadily in the second decade, especially from 2016 . About $53.4 \%$ of the publications were found in the 20 most productive journals. The three core journals related to this field were Energy Policy, Renewable Energy, and Journal of Southern Africa. Among the 81 subject categories, Energy Fuels accounted for $44.8 \%$ of all the articles. More articles were related to the subject of Environment and Economics than to Engineering. Analysis of the performance of authors, institutions, and countries showed that South Africa contributed the most to publications in this field, accounting for $24 \%$ of the total publications, followed by the USA and Germany. South Africa was also the most academically influential country in terms of total citations and h-index. Cooperation network analysis showed that South Africa had the highest number of collaborations. The strongest collaborative links were seen between South Africa and the USA, South Africa and UK, and Germany and UK. Univ Cape Town had the highest number of collaborations, but the strongest cooperative link was between Stellenbosch University in South Africa and Victoria Univ Wellington in New Zealand, indicating strong intercontinental cooperation. Collaboration between African countries was, however relatively lower. Author keyword analysis showed that South Africa was the most studied region and 'solar energy' received the most attention under renewable energy sources. An analysis of the development of keywords in the five continental regions showed that articles published outside Africa had comparatively more dynamic keywords over different time stages. Research hotspots under different study categories also revealed that 'solar energy, ' $\mathrm{CO}_{2}$ emissions' and 'rural electrification' are hot issues that have gained more attention over the years.

\section{Declarations}

Acknowledgments: The authors would like to thank Prof. Mao Guozhu and Prof. Haifeng Liu from Tianjin University for their enormous supervision and guidance towards successfully completing the current study.

Author Contributions: Conceptualization, SA and JDA; methodology, SA; software, JDA; validation, EMA; formal analysis, SA; investigation, JDA; resources, EMA; data curation, EMA; writing-original draft preparation, SA; writing-review and editing, JDA; visualization, SA and JDA.

Funding: This research received no external funding.

Availability of data and materials;

The datasets generated and analysed throughout the current study are available in the Web of Science Core Collection.

\section{Ethics approval and consent to participate;}

Not applicable 


\section{Consent for publication;}

Not applicable

\section{Competing interests;}

The authors declare that they have no competing interests

\section{References}

Adams S, Klobodu EKM, Opoku EEO (2016): Energy consumption, political regime and economic growth in sub-Saharan Africa. Energy Policy 96, 36-44. https://doi.org/10.1016/j.enpol.2016.05.029

Adewuyi AO, Awodumi OB (2017): Biomass energy consumption, economic growth and carbon emissions: Fresh evidence from West Africa using a simultaneous equation model. Energy 119, 453-471. https://doi.org/10.1016/j.energy.2016.12.059

Africa Report 2015: Renewables; green today, cheap tomorrow. Available at: https://www.theafricareport.com/2917/energy-green-today-cheap-tomorrow/ Date Accessed:3rd April 2021.

African Development Bank 2017: The new deal on energy for Africa. A transformative partnership to light up and power Africa by 2025. Update of implementation.Available at: https://www.afdb.org/fileadmin/uploads/afdb/Documents/Generic-Documents/Brochure_New_Deal_2_red.pdf. Date Accessed:16th April 2021.

Aguirre M, Ibikunle G (2014): Determinants of renewable energy growth: A global sample analysis. Energy Policy 69, $374-384$.

https://doi.org/10.1016/j.enpol.2014.02.036

Ahlborg H, Boräng F, Jagers SC, Söderholm P (2015): Provision of electricity to African households: The importance of democracy and institutional quality. Energy Policy 87, 125-135. https://doi.org/10.1016/j.enpol.2015.09.002

Al-Kharabsheh S (2003): Theoretical and experimental analysis of water desalination system using low grade solar heat

Aliyu AK, Modu B, Tan CW (2018): A review of renewable energy development in Africa: A focus in South Africa, Egypt and Nigeria. Renewable and Sustainable Energy Reviews 81, 2502-2518. https://doi.org/10.1016/j.rser.2017.06.055

Amin M, Mabe M (2004): Impact factors use and abuse. International Journal of Environmental Science Technology 1(1).

Ben Jebli M, Ben Youssef S, Ozturk I (2015): The Role of Renewable Energy Consumption and Trade: Environmental Kuznets Curve Analysis for Sub-Saharan Africa Countries. African Development Review 27, 288-300. https://doi.org/10.1111/1467-8268.12147

Boisgibault L, Al Kabbani F (2020): Energy Transition in Metropolises, Rural Areas, and Deserts

Boko M, Niang I, Nyong A, Vogel C, Githeko A, Medany M, Osman-Elasha B, Tabo R, Yanda P 2007: Africa. Climate Change 2007: Impacts, Adaptation and Vulnerability. Contribution of Working Group II to the Fourth Assessment Report of the Intergovernmental Panel on Climate Change, M.L. Parry, O.F. Canziani, J.P. Palutikof, P.J. van der Linden and C.E. Hanson, Eds., Cambridge University Press, Cambridge UK

BP (2020): Statistical Review of World Energy - all data 1965-2019

Braun T, Glänzel W, Schubert A (2006): A Hirsch-type index for journals. Scientometrics 69, 169-173. 10.1007/s11192-006-0147-4

Brundtland GH, Khalid M (1987): Our common future. Oxford University Press, Oxford, GB

Casado E, Serrano-López A, De filippo D, Lascurain M (2014): Bibliometric analysis of Chinese-Spanish collaboration in renewable energy research. Science Focus 9, 43-52.

Chen D, Liu Z, Luo Z, Webber M, Chen J (2016): Bibliometric and visualized analysis of emergy research. Ecological Engineering 90, $285-293$.

https://doi.org/10.1016/j.ecoleng.2016.01.026

de Vries BJM, van Vuuren DP, Hoogwijk MM (2007): Renewable energy sources: Their global potential for the first-half of the 21 st century at a global level: An integrated approach. Energy Policy 35, 2590-2610. https://doi.org/10.1016/j.enpol.2006.09.002

Deichmann U, Meisner C, Murray S, Wheeler D (2011): The economics of renewable energy expansion in rural Sub-Saharan Africa. Energy Policy 39, $215-227$. https://doi.org/10.1016/j.enpol.2010.09.034

Demirbas A (2009): Global Renewable Energy Projections. Energy Sources, Part B: Economics, Planning, and Policy 4, 212-224. 10.1080/15567240701620499

Demissew Beyene S, Kotosz B (2020): Testing the environmental Kuznets curve hypothesis: An empirical study for East African countries. International Journal of Environmental Studies 77, 636-654. 10.1080/00207233.2019.1695445 
Dovì VG, Friedler F, Huisingh D, Klemeš JJ (2009): Cleaner energy for sustainable future. Journal of Cleaner Production 17, $889-895$.

https://doi.org/10.1016/j.jclepro.2009.02.001

Du H, Li N, Brown MA, Peng Y, Shuai Y (2014): A bibliographic analysis of recent solar energy literatures: The expansion and evolution of a research field. Renewable Energy 66, 696-706. https://doi.org/10.1016/j.renene.2014.01.018

Esso LJ, Keho Y (2016): Energy consumption, economic growth and carbon emissions: Cointegration and causality evidence from selected African countries. Energy 114, 492-497. https://doi.org/10.1016/j.energy.2016.08.010

Garfield E (2006): The History and Meaning of the Journal Impact Factor. JAMA 295, 90-93. 10.1001/jama.295.1.90

Góralczyk M (2003): Life-cycle assessment in the renewable energy sector. Applied Energy 75, 205-211. https://doi.org/10.1016/S0306-2619(03)00033-3

Gyamfi S, Derkyi NSA, Asuamah EY, Aduako IJA (2018): Chapter 6 - Renewable Energy and Sustainable Development. In: Kabo-Bah A, Diji CJ (Editors), Sustainable Hydropower in West Africa. Academic Press, pp. 75-94

Hafner M, Tagliapietra S, de Strasser L (2018): Prospects for Renewable Energy in Africa, Energy in Africa: Challenges and Opportunities. Springer International Publishing, Cham, pp. 47-75

Halkos G, Managi S (2016): Special issue on “Growth and the environment”. Environmental Economics and Policy Studies 18, 273-275. 10.1007/s10018-0160151-8

Hammons TJ, Blyden BK, Calitz AC, Gulstone AB, Isekemanga E, Johnstone R, Paluku K, Simang N, Taher F (2000): African electricity infrastructure interconnections and electricity exchanges. IEEE Transactions on Energy Conversion 15, 470-480. 10.1109/60.900510

Hirsch JE (2005): An index to quantify an individual's scientific research output. Proc. Natl. Acad. Sci. USA 102, 16569-16572. 10.1073/pnas.0507655102 \% J Proceedings of the National Academy of Sciences of the United States of America

Hood WW, Wilson CS (2001): The Literature of Bibliometrics, Scientometrics, and Informetrics. Scientometrics 52, 291. 10.1023/A:1017919924342

IEA (2014): Africa energy outlook

IEA (2019): Africa Energy Outlook 2019, IEA, Paris

IEA (2020): SDG7: Data and Projections, IEA, Paris

IEA, IRENA, UNSD, World Bank, WHO (2020): Tracking SDG 7: The Energy Progress Report, World Bank, Washington DC

IEA (2018): Global Status Report

Im KS, Pesaran MH (2003): On the Panel Unit Root Tests Using Nonlinear Instrumental Variables.

IRENA (2015): Africa 2030: Roadmap for a Renewable Energy Future, IRENA, Abu Dhabi

Karekezi S, Kithyoma W (2003): Renewable energy in Africa: prospects and limits, The workshop for African energy experts on operationalizing the NEPAD energy initiative, pp. 2-3

Kessides IN (2014): Powering Africals sustainable development: The potential role of nuclear energy. Energy Policy 74, S57-S70.

https://doi.org/10.1016/j.enpol.2014.04.037

Kohler M (2013): CO2 emissions, energy consumption, income and foreign trade: A South African perspective. Energy Policy 63, $1042-1050$.

https://doi.org/10.1016/j.enpol.2013.09.022

Law EW, Prasad AA, Kay M, Taylor RA (2014): Direct normal irradiance forecasting and its application to concentrated solar thermal output forecasting - A review. Solar Energy 108, 287-307. https://doi.org/10.1016/j.solener.2014.07.008

Levin A, Lin C-F, James Chu C-S (2002): Unit root tests in panel data: asymptotic and finite-sample properties. Journal of Econometrics 108, 1-24. https://doi.org/10.1016/S0304-4076(01)00098-7

Lewis NS, Nocera DG (2006): Powering the planet: Chemical challenges in solar energy utilization. Proceedings of the National Academy of Sciences 103, 15729. 10.1073/pnas.0603395103

Maji IK (2015): Does clean energy contribute to economic growth? Evidence from Nigeria. Energy Reports 1, 145-150.

https://doi.org/10.1016/j.egyr.2015.06.001

Maji IK, Sulaiman C, Abdul-Rahim AS (2019): Renewable energy consumption and economic growth nexus: A fresh evidence from West Africa. Energy Reports 5, 384-392. https://doi.org/10.1016/j.egyr.2019.03.005 
Mandelli S, Barbieri J, Mattarolo L, Colombo E (2014): Sustainable energy in Africa: A comprehensive data and policies review. Renewable and Sustainable Energy Reviews 37, 656-686. https://doi.org/10.1016/j.rser.2014.05.069

Mao G, Liu X, Du H, Zuo J, Wang L (2015a): Way forward for alternative energy research: A bibliometric analysis during 1994-2013. Renewable and Sustainable Energy Reviews 48, 276-286. https://doi.org/10.1016/j.rser.2015.03.094

Mao G, Zou H, Chen G, Du H, Zuo J (2015b): Past, current and future of biomass energy research: A bibliometric analysis. Renewable and Sustainable Energy Reviews 52, 1823-1833. https://doi.org/10.1016/j.rser.2015.07.141

Menyah K, Wolde-Rufael Y (2010): Energy consumption, pollutant emissions and economic growth in South Africa. Energy Economics 32, $1374-1382$. https://doi.org/10.1016/j.eneco.2010.08.002

Moyo JM, Krüger R, Belamine D (2017): Concentrated Solar Power (CSP) and Photovoltaic (PV): Has time come for solar energy in Africa?

Mutezo G, Mulopo J (2021): A review of Africa's transition from fossil fuels to renewable energy using circular economy principles. Renewable and Sustainable Energy Reviews 137, 110609. https://doi.org/10.1016/j.rser.2020.110609

Nouni MR, Mullick SC, Kandpal TC (2008): Providing electricity access to remote areas in India: An approach towards identifying potential areas for decentralized electricity supply. Renewable and Sustainable Energy Reviews 12, 1187-1220. https://doi.org/10.1016/j.rser.2007.01.008

Oluoch S, Lal P, Susaeta A (2021): Investigating factors affecting renewable energy consumption: A panel data analysis in Sub Saharan Africa. Environmental Challenges 4, 100092. https://doi.org/10.1016/j.envc.2021.100092

Organization IS (1997): ISO 14040: Environmental Management-Life Cycle Assessment-Principles and Framework

Ozturk I, Bilgili F (2015): Economic growth and biomass consumption nexus: Dynamic panel analysis for Sub-Sahara African countries. Applied Energy 137, 110-116. https://doi.org/10.1016/j.apenergy.2014.10.017

Pegels A (2010): Renewable energy in South Africa: Potentials, barriers and options for support. Energy Policy 38, $4945-4954$.

https://doi.org/10.1016/j.enpol.2010.03.077

Pouris A (2016): A bibliometric assessment of energy research in South Africa. South African Journal of Science 112, 1-8.

Quah D (1994): Exploiting cross-section variation for unit root inference in dynamic data. Economics Letters 44, 9-19. https://doi.org/10.1016/01651765(93)00302-5

REN21 2017: Global status report

Renewable Desalination (2010): Renewable Desalination Market Analysis Report (2010) (Oceania, South Africa, Middle East \& North Africa). Available at: http://www.aquamarinepower.com/sites/resources/Reports/2470/Renewable\%20desalination\%20market\%20analysis\%20\%200ceania\%20South\%20Africa\%2 Date Accessed:20th April 2021

Sarkodie SA, Strezov V (2019): Effect of foreign direct investments, economic development and energy consumption on greenhouse gas emissions in developing countries. Science of The Total Environment 646, 862-871. https://doi.org/10.1016/j.scitotenv.2018.07.365

Sbia R, Shahbaz M, Hamdi H (2014): A contribution of foreign direct investment, clean energy, trade openness, carbon emissions and economic growth to energy demand in UAE. Economic Modelling 36, 191-197. https://doi.org/10.1016/j.econmod.2013.09.047

Schwartz FW, Fang YC, Parthasarathy S (2005): Patterns of evolution of research strands in the hydrologic sciences. Hydrogeology Journal $13,25-36$. $10.1007 /$ s10040-004-0423-4

Shafik N, Bandyopadhyay S (1992): Economic growth and environmental quality: time-series and cross-country evidence, 904

Shahbaz M, Solarin SA, Sbia R, Bibi S (2015): Does energy intensity contribute to CO2 emissions? A trivariate analysis in selected African countries. Ecological Indicators 50, 215-224. https://doi.org/10.1016/j.ecolind.2014.11.007

Shatat M, Riffat SB (2012): Water desalination technologies utilizing conventional and renewable energy sources. International Journal of Low-Carbon Technologies 9, 1-19. 10.1093/ijlct/cts025

Shatat M, Worall M, Riffat S (2013): Opportunities for solar water desalination worldwide: Review. Sustainable Cities and Society $9,67-80$. https://doi.org/10.1016/j.scs.2013.03.004

Simsek HA, Simsek N (2013): Recent incentives for renewable energy in Turkey. Energy Policy 63, 521-530. https://doi.org/10.1016/j.enpol.2013.08.036

Small H (1973): Co-citation in the scientific literature: A new measure of the relationship between two documents. Journal of the American Society for Information Science 24, 265-269. https://doi.org/10.1002/asi.4630240406

Soetaert W, Vandamme EJ (2009): Biofuels in Perspective, Biofuels, pp. 1-8

Page $17 / 23$ 
SolarReserve 2015: Letsatsi.Available at: https://en.reset.org/blog/africas-largest-solar-power-project-completed-01232015 Date Accessed:3rd April 2021.

Szabó S, Bódis K, Huld T, Moner-Girona M (2011): Energy solutions in rural Africa: mapping electrification costs of distributed solar and diesel generation versus grid extension. Environmental Research Letters 6, 034002. 10.1088/1748-9326/6/3/034002

Teichmann D, Arlt W, Wasserscheid P (2012): Liquid Organic Hydrogen Carriers as an efficient vector for the transport and storage of renewable energy. International Journal of Hydrogen Energy 37, 18118-18132. https://doi.org/10.1016/j.ijhydene.2012.08.066

Trotter PA, McManus MC, Maconachie R (2017): Electricity planning and implementation in sub-Saharan Africa: A systematic review. Renewable and Sustainable Energy Reviews 74, 1189-1209. https://doi.org/10.1016/j.rser.2017.03.001

Varun, Prakash R, Bhat IK (2010): A figure of merit for evaluating sustainability of renewable energy systems. Renewable and Sustainable Energy Reviews 14, 1640-1643. https://doi.org/10.1016/j.rser.2010.02.003

Viebahn P, Lechon Y, Trieb F (2011): The potential role of concentrated solar power (CSP) in Africa and Europe-A dynamic assessment of technology development, cost development and life cycle inventories until 2050. Energy Policy 39, 4420-4430. https://doi.org/10.1016/j.enpol.2010.09.026

Whitesides GM, Crabtree GW (2007): Don't Forget Long-Term Fundamental Research in Energy. Science 315, 796-798. 10.1126/science.1140362

World Bank (2015): World Development Indicators, World Bank, Washington, DC

World Nuclear Association (2013): World Uranium Mining Production

World Resource Initiative (2009): Climate analysis indicators tool

Xu X, Wei Z, Ji Q, Wang C, Gao G (2019): Global renewable energy development: Influencing factors, trend predictions and countermeasures. Resources Policy 63, 101470. https://doi.org/10.1016/j.resourpol.2019.101470

Yaoyang X, Boeing WJ (2013): Mapping biofuel field: A bibliometric evaluation of research output. Renewable and Sustainable Energy Reviews 28 , $82-91$. https://doi.org/10.1016/j.rser.2013.07.027

Younger PL (2014): Missing a trick in geothermal exploration. Nature Geoscience 7, 479-480. 10.1038/ngeo2193

\section{Figures}

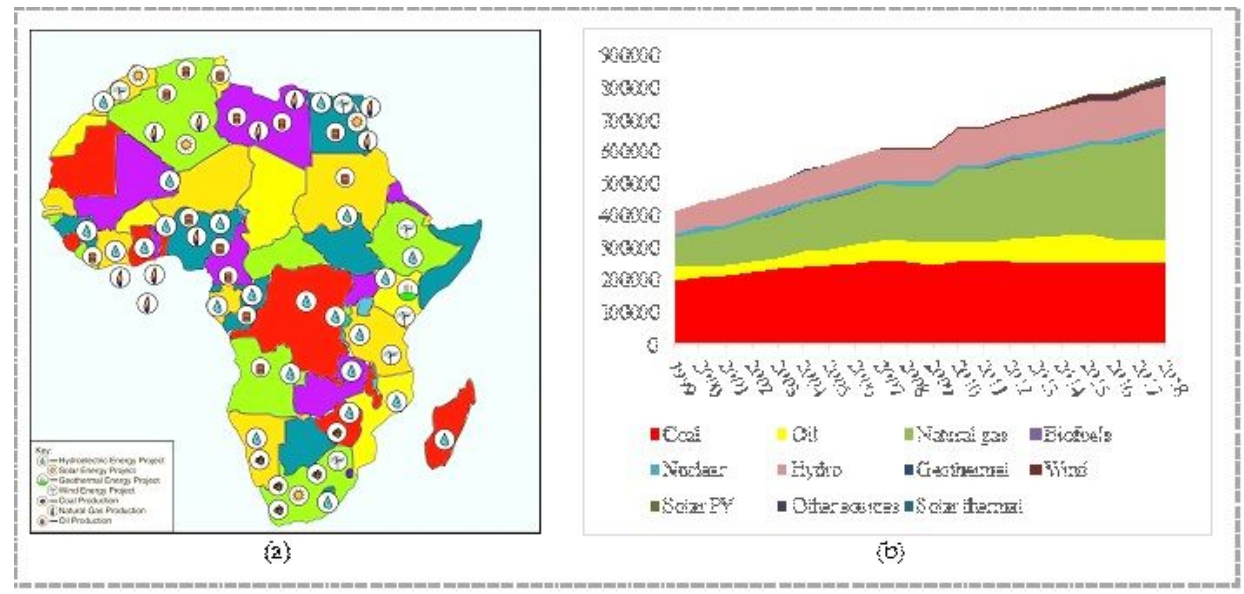

Figure 1

Description of energy sources in Africa: (a) Geographical distribution of energy sources across the continent, (b) Electricity generation by source (Gigawatt hour) in Africa (IEA 2019) 


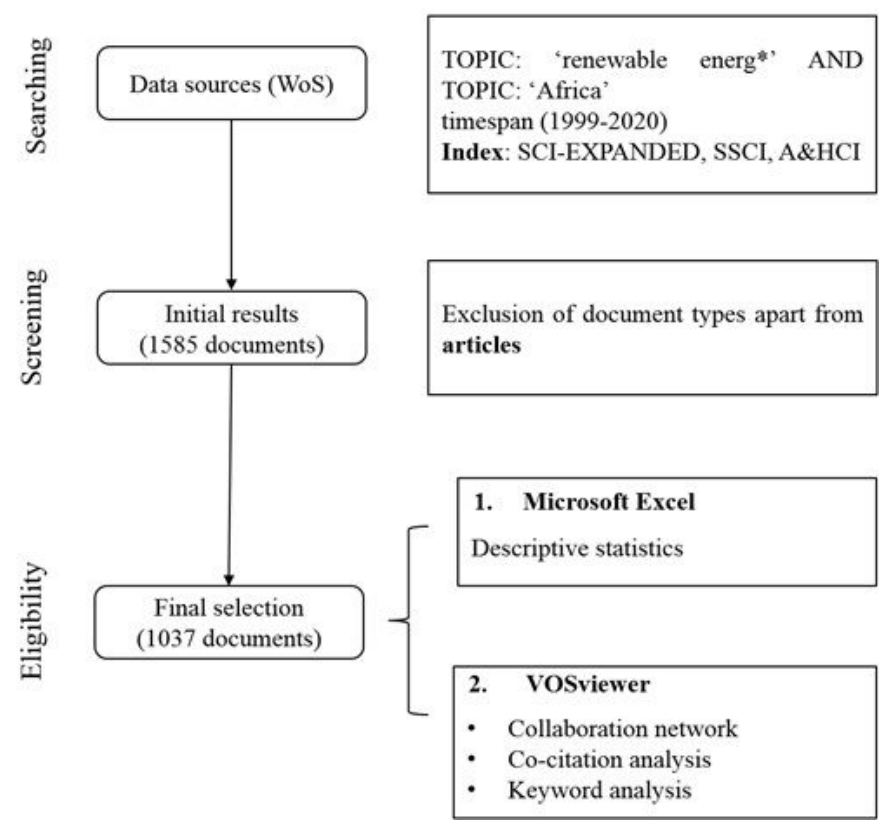

Figure 2

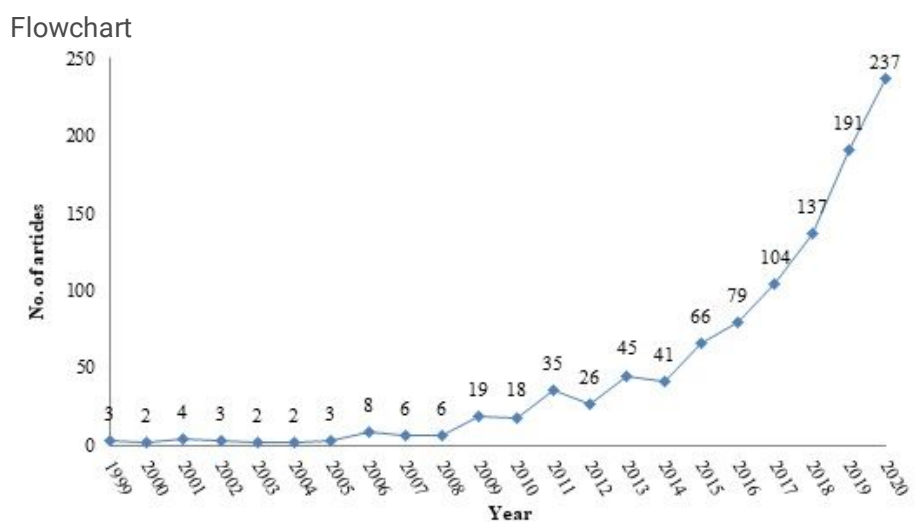

Figure 3

Development of publications from 1999 to 2020

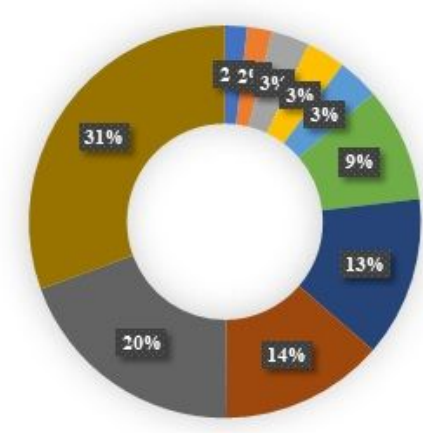

- Mbltidisciplinary Sciences

=Development S tudies

Engineering Chemical

=Engineering Environmental

-Thermodynamics

- Economics

- Environmental Studies

- Green Sustainable Science

Technology
-Environmental Sciences

Energy Fuels

Figure 4

Distribution of top 10 subject categories 


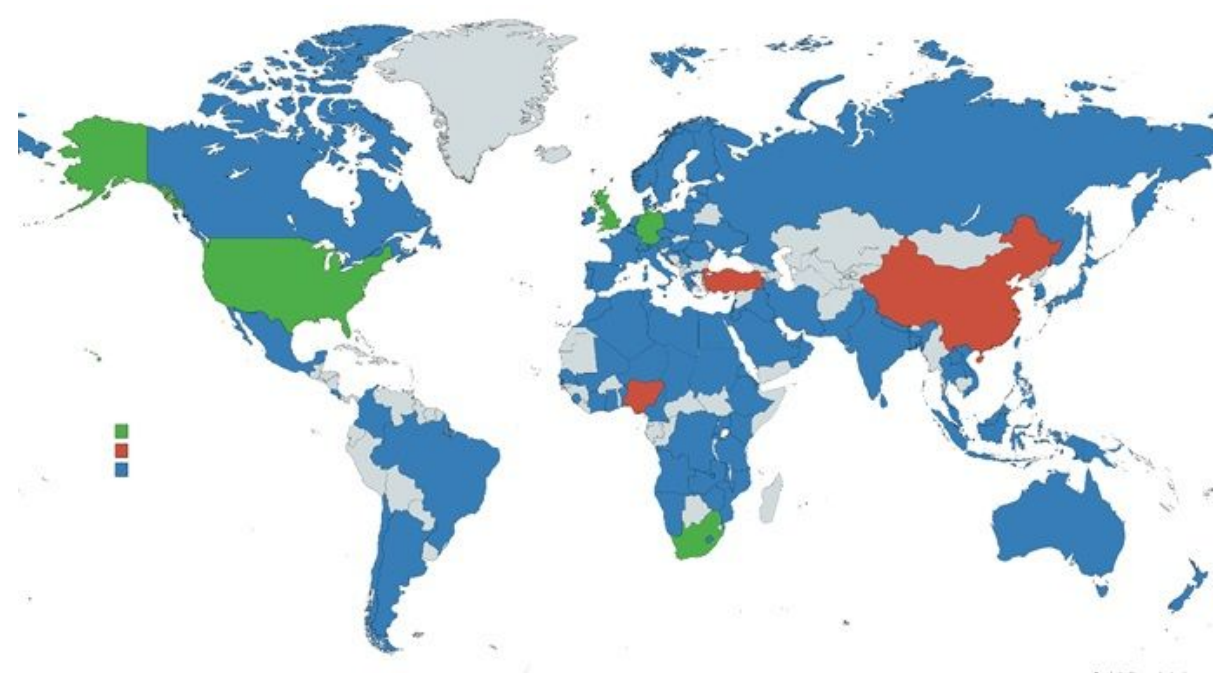

\section{Figure 5}

Global distribution of published articles

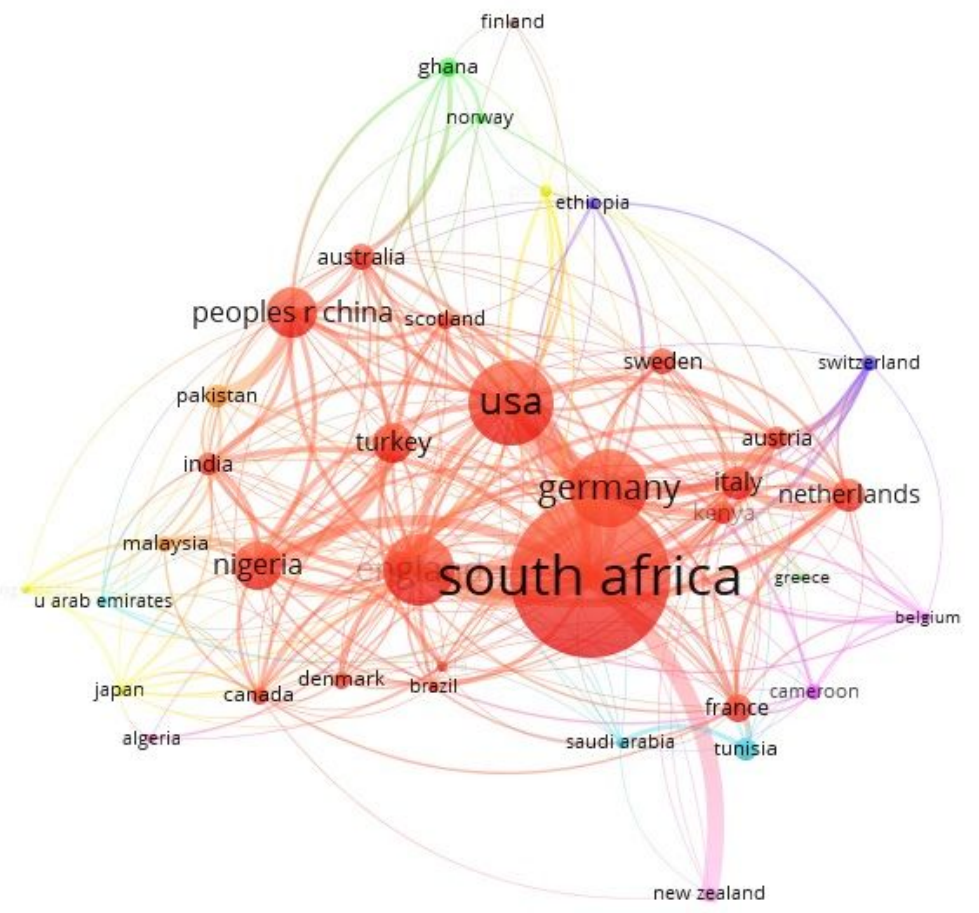

\section{Figure 6}

Academic collaboration among top 39 most productive countries 


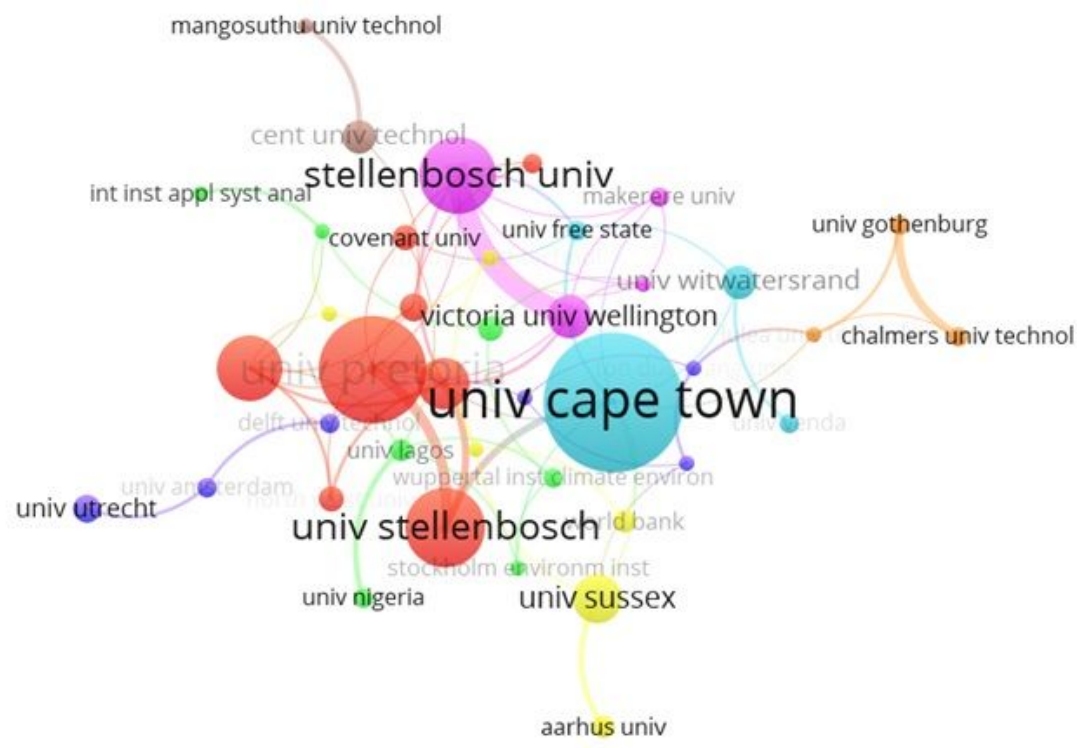

Figure 7

Academic collaboration among top 32 most productive institutions

sebitosi, ab komendantova, $\mathrm{n}$
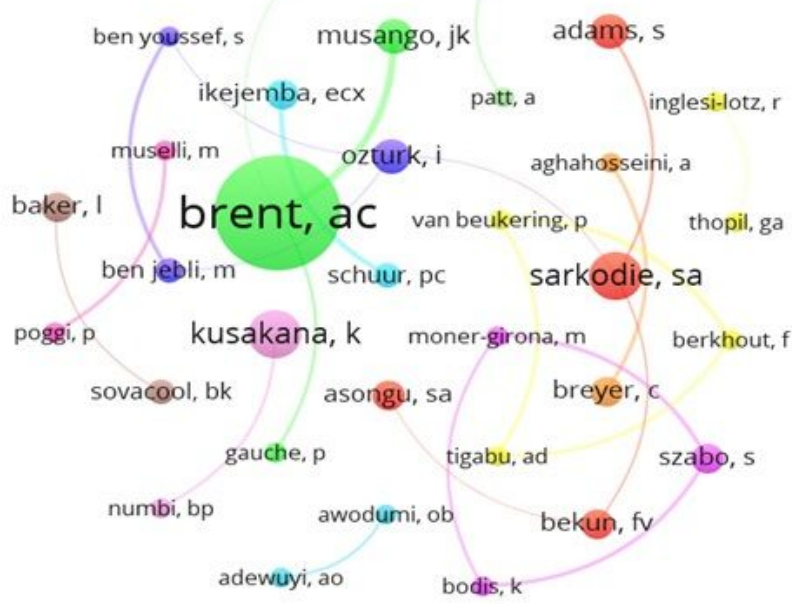

\section{Figure 8}

Academic collaboration among top 35 most productive authors 


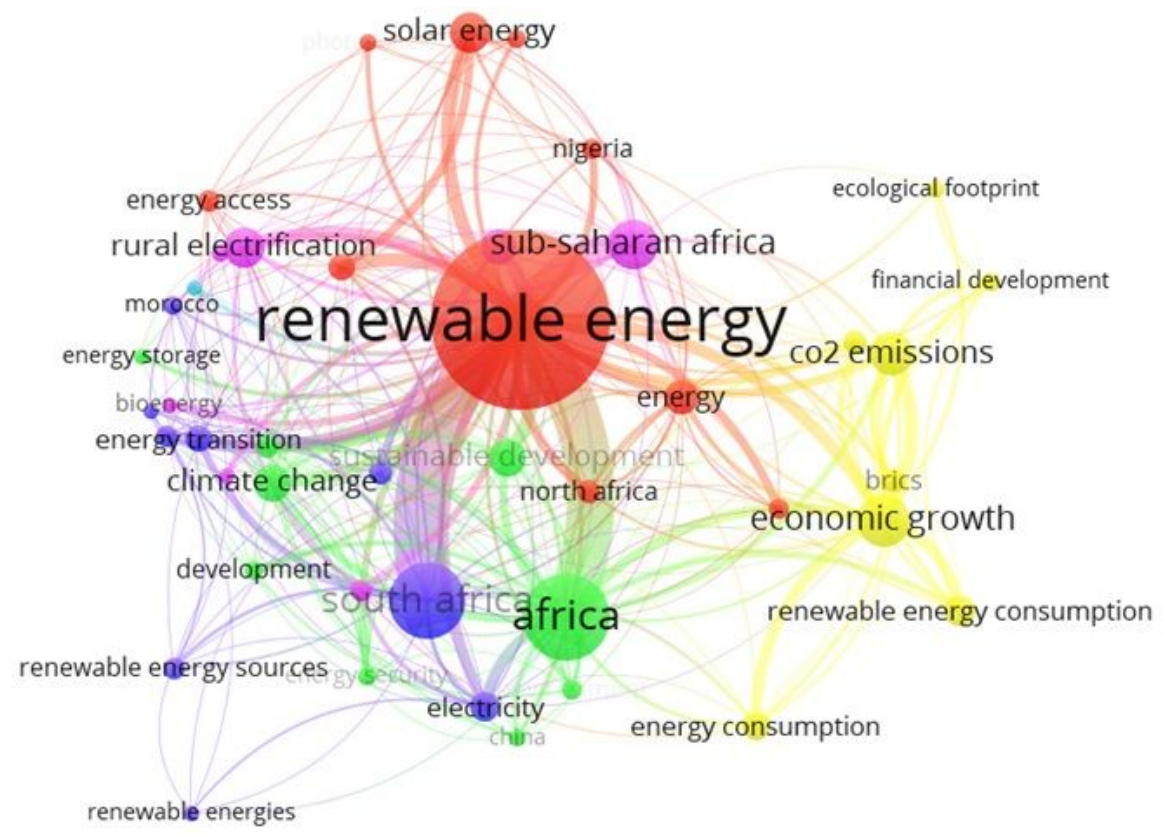

Figure 9

Co-occurrence network of the 44 most frequently used author keywords

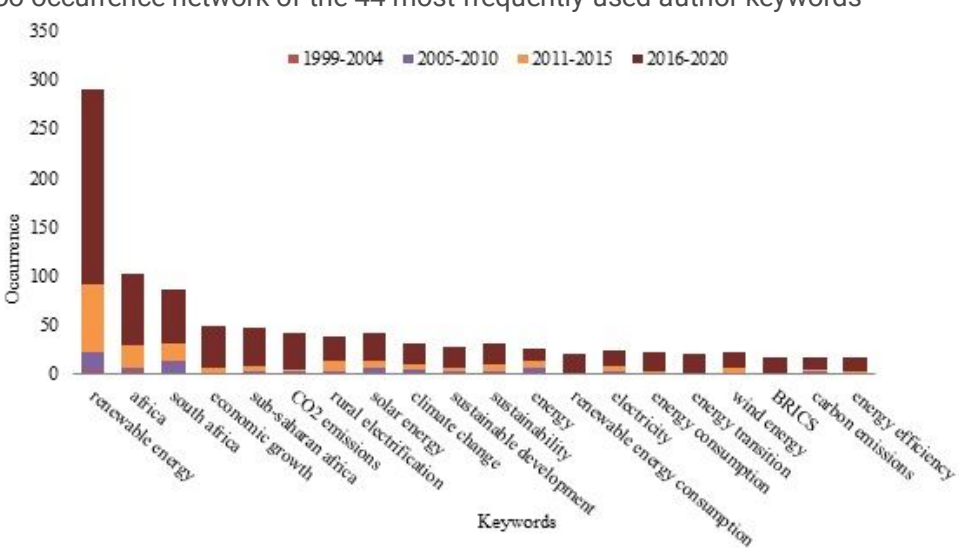

Figure 10

Development of author keywords in four different stages 


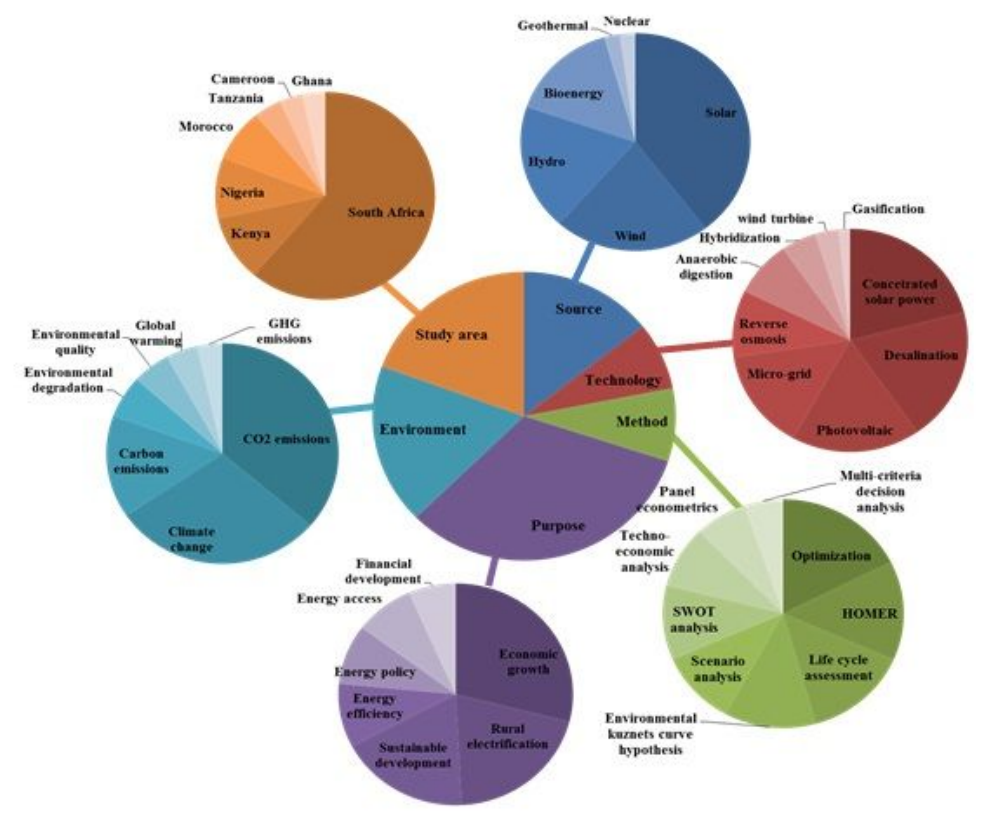

Figure 11

Categories of author keywords

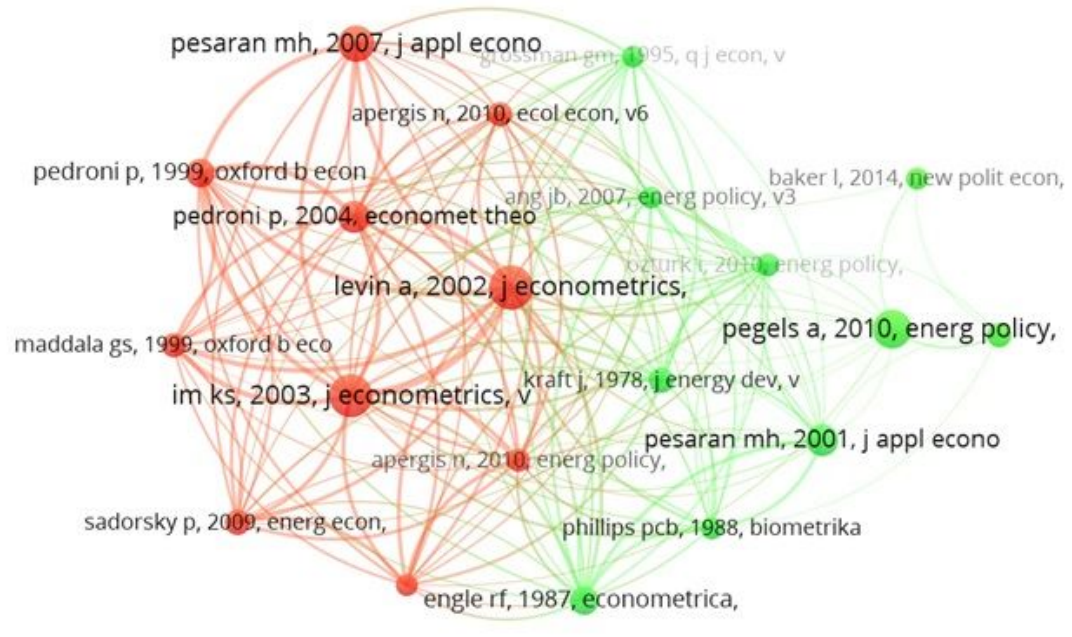

\section{Figure 12}

Co-citation network among top 31 most cited references 